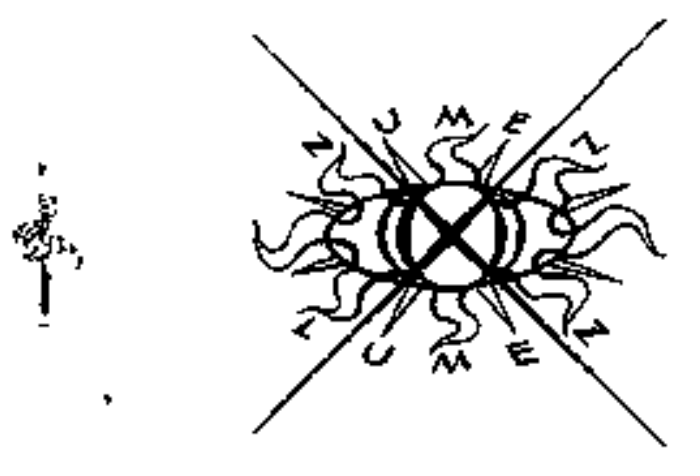

\title{
THE MASTER
}

\section{UNIVERSITY \\ OF}

WISCONSIN

\section{DEPARTMENT OF}

\section{ELECTRICAL ENGINEERING}

'Plasma Instab111ties and Waves Exclted by an Anlsotropte Energy Distribution Produced by Electron Cyclotron Resonance"

\section{U.S. Atomic Energy Comission} Contract No. AT (11-1) 1695

$$
\text { REPORT NO. COO-1695-26 }
$$

Narch 15, 1970 


\section{DISCLAIMER}

This report was prepared as an account of work sponsored by an agency of the United States Government. Neither the United States Government nor any agency Thereot, nor any of their employees, makes any warranty, express or implied, or assumes any legal liability or responsibility for the accuracy, completeness, or usefulness of any information, apparatus, product, or process disclosed, or represents that its use would not infringe privately owned rights. Reference herein to any specific commercial product, process, or service by trade name, trademark, manufacturer, or otherwise does not necessarily constitute or imply its endorsement, recommendation, or favoring by the United States Government or any agency thereof. The views and opinions of authors expressed herein do not necessarlly state or reflect those of the United States Government or any agency thereof. 


\section{DISCLAIMER}

Portions of this document may be illegible in electronic image products. Images are produced from the best available original document. 


\section{QUARTERLY PROGRESS REPORT NO. 12}

Plasua Instabilities and Waves Exclted by an Anlsotropic Energy Distribution Produced by Electron Cyclotron Resonance

Contract No. AT (11-1) 2695

U.S. Atomic Energy Cowntesion

J. L. Shohet

J. C. Sprote

S, R. Seshadri

D. G. S. Greene

K. A. Connor

K. E. Trnka

N. W. Schwartz
Principal Investigator (on leave) Co-Investigator Co-Investigator Graduate Research Aasistant Graduate Research Assistant Student Technictan Student Techrictan

Marck 15, 1970

Departuent of Electrieal Bngineering The University of Wisconsin Madison, Wisconsin 53706

- LEGAL NOTICE

dמل

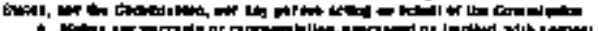

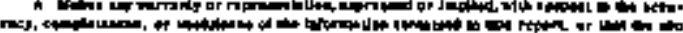

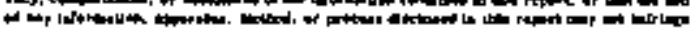

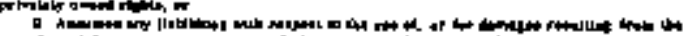

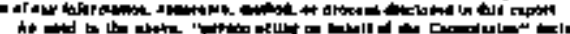

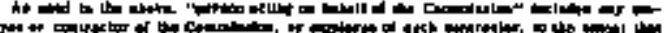

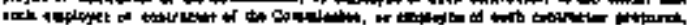

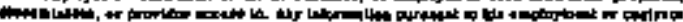

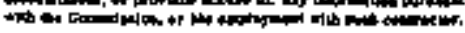

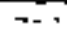

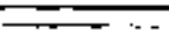


1. INTRODUCTION

J. C. Sprott

Theoretical work during the pertod Decenber 15, 1969 - March 14, 1970 hes centered on two mafor problomg: 1) calculation of rf heating rates by analytical means and by computer simulation, and 2) a continuation of the calculations of the free-free brongstrahlung from a relativiatic anteotropic plasms .

The analytical heating calculatione treat the case of a cold, tenuous plagms in an arbitrary nom-unfform magnetic fleld. The heating rate 18 expressed in terms of the magnetic field gradient in the viciatty of cyclotron resonance and the dengity distribution. The results are in good agreewent with other theoretical works and the limitations do not appear to be too restrictive.

Computer sfmulation has been uged to study electron eyclotron heating In a unform magnetlc field. Electrons and long are free to move in the two dimensfons perpendicular to $\vec{B}$ under the influence of the external de magnetic and $r$ electric fields and the self-consistent space charge electric field. The resultg have shown heating of both electrong and lons and indication of an instability after the $r f$ is turned off.

Calculations are being node of the polarization of the bremsstrahlung and corrections to the bremsstralifung spectra due to the finlee mass of the nucleus.

The experimental progran has concentrated on developing Langutr probe techniques for use on the sagnetic nitror device. The probes work surprialngly well, and do not appear to perturb the plasma appreclably. Decalled measurements of floating potential, density, and tenperature of the cold plasma component In the afterglow have been made vo position and time for a variety of heating conditions. 


\section{CALCULATION OF ELECTRON CYCLOTRON HFATING RATES}

J. C. Sprote

A. Theoretical model.

Consider a plasma confined In a cavity of arbitrary atze and shape by a static non-uniforw nagnetic fleld $\vec{B}(\vec{x})$ in the presence of an rf electric field $\vec{E}_{0}(\vec{r}, t) e^{\text {lut }}$. Aosume a plasma density suffleiently low that the waves freely penetrate the plasna and a plasma pressure auffictently low that the magnetic field is unperturbed $\left(1, e ., B=2 \mu_{0} p / B^{2}<<1\right)$.

We define a fuaction $\psi$ which is constant on a flux surface and has a value equal to the mageetic flux enclesed by that surface. The magnetic fleld lines lie in the surfaceg and may or may not be confined in the cavicy. An orthogonal coordinate systen will be used in which $\hat{\psi}$ 1s a unit vector notalal to a flux surface and $\hat{l} 18$ andt vector $1 \mathrm{a}$ the direction of $\vec{B}$. This system is conventent because plasms energy flows readily in the $\hat{\ell}$ direction and because in many axisymetric and linear geometries the coordinate orthogonal to $\hat{l}$ and $\hat{\psi}$ is ignorable.

The power absorbed per unit volume in a resiative dielectric medium can be expreased in terms of a real tengor conductivity $\overleftrightarrow{a} a$

$$
\frac{d P}{d v}=(\stackrel{\leftrightarrow}{a} \cdot \vec{E}) \cdot \vec{E},
$$

or, in our coordinates,

$$
\frac{d P}{d \psi}=\int\left(O_{1} E_{1}^{2}+O_{n} E_{n}^{2}\right) d L / B
$$

The perpendicular and parallel conductivitieg of a cold, tenuous plasna can be expressed in terms of a collision frequency $v$ for $v<<\omega$ as

$$
\sigma_{1}=E_{0} w_{p}^{2} v\left[\omega^{2}+w_{c}^{2}\right] /\left(\left(\omega^{2}-w_{c}^{2}\right)^{2}+4 w^{2} v^{2}\right]
$$

and

$$
\sigma_{11}=\varepsilon_{0}{ }^{2} w / \omega^{2},
$$


where $w_{p}$ is the plasma frequency and $\omega_{c}$ is the cyclotron frequency. For v<cu, nost of the contribution to the integral in equation (2) comeg from the resonance at $\omega^{-} w_{c}$, and we can expand $B(f)$ In a Taylor sertes about its resonance value, retaining onty the first order term:

$$
B(\ell)=B_{a}+q\left|\nabla_{0} B\right| \text {. }
$$

where $\ell=0$ ig taken where $B$ muw/e and the subscript "o" refers to the value of a quantity at $\ell=0$. If the electric fleld and dengtty vary slowly over the width of the resonance, the integral in equation (2) can be evaluated for $-\infty<l<\infty$ to get the result

$$
\frac{\mathrm{dP}}{\mathrm{d} \psi}=\frac{\pi_{0} e E_{t 0}^{2}}{2 \mathrm{~B}_{0}\left|\nabla_{\mathrm{no}} \mathrm{B}\right|} \text {. }
$$

The corresponding heating rate is

$$
\frac{d \bar{W}}{d t}(\psi)=\frac{d P}{d \psi} / \int \frac{n d f}{\bar{B}}=\frac{n_{0} e E_{10}^{2}}{2 B_{0}\left|\nabla_{\omega 0} B\right| / n d l / B} .
$$

B. Comparison with other works.

The same result can be obtained by a simple phenomenological argument. The average energy galned by an electron during one transit through resonance can be written as

$$
\overline{\Delta W}=\frac{1}{2} \text { m } \overline{\Delta v_{+}^{2}}=\frac{e^{2} E_{L O}^{2}}{2 m} r^{2},
$$

Where $T$ is the tine during which the electron stays in phase oith the electric fleld, or che cine requited for the electron to cross the resonance region, Kawagura and Terashing ${ }^{1}$ used the above expresaton to calculate the heatiag rate tn the TP-M nach1ne at Nagoya Universtity (Japan). Lichtenberg, et al. ${ }^{2}$ have also proposed a similar expression, differtag only by a numerical factor of order unity.

The transit time of an electron through resonance can be approximated by a method suggested by Guest ${ }^{3}$ and by Ard ${ }^{4}$ : 


$$
\int_{0}^{T}\left(\omega_{c}-\omega\right) d t=\frac{\omega \mid \nabla_{n_{0}} B d}{\bar{B}_{0}} \int_{0}^{T} v_{\omega} t d t=\frac{T}{2},
$$

to get the result,

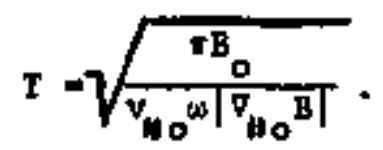

The resulting energy gain is

$$
\overline{\Delta W}=\frac{\pi \mathrm{eE}}{2 \mathrm{v}_{10} \mathrm{LO}_{\mathrm{O}} \mathrm{BT}} \text {. }
$$

Kuckes 5 arrived at an identical regult by solving explicitly the equation of motion of an election that moves through the resonance region with constant parallel veloctty in a fleld with a constant gradient parallel to $\mathrm{s}$.

The power absorbed by a group of particles is found by multiplying the average energy gatned during one transit by the flux of particlas through resonance:

$$
d P=\overline{D W} n_{0} y_{10} d A=\frac{m_{0} e E_{10}^{2}}{2 B_{0} \mid \nabla_{00} \nabla_{0}} d \psi .
$$

The result is identical to equation (3).

Several authors have considered the spectal case of a straight nagnetic field of the form.

$$
B(z)=B(0)\left(1+B Z^{2}\right),
$$

fn which electrons execute ninusotdal osctllations:

$$
z(t)=z_{y} \sin w_{\beta} t,
$$

where

$$
\omega_{B}=\sqrt{\beta} v_{L}(0)
$$

For a group of electrons that wirror at $Z_{M}$, the density distribution is given by 


$$
n(z)=\left\{\begin{array}{cc}
\frac{a_{0} B(z) v_{0 O}}{B_{0} v_{H}(z)}+ & \text { for } z \leq z_{M} \\
0 & \text { for } z>z_{M}
\end{array}\right.
$$

where $v_{w}(z)=v_{\perp}(0) \sqrt{B} \sqrt{z_{M}^{2}-z^{2}}$.

Substituting into equation (4) gives

$$
\frac{\mathrm{d} \overline{\mathrm{W}}}{\mathrm{dt}}=\frac{\mathrm{eE}_{1 \mathrm{D}}^{2}}{2 \mathrm{~B}_{\mathrm{D}} \sqrt{\delta}} \frac{\mathrm{r}}{\mathrm{r}-\mathrm{I}}
$$

where $\delta=\frac{z_{\mathrm{H}}^{2}}{z_{\mathrm{o}}^{2}}-1$ and $\mathrm{r}=\mathrm{B}_{\mathrm{o}} / \mathrm{B}(0)$.

Grawe $^{6}$ has treated the sane problem by solving explicltly the equation of motion of a relativiste electron in a parabolic magnetic field. In the non-relativistic linit, his tesult io

where

$$
\frac{d W}{d t}=\frac{\pi e E_{\perp 0}^{2}}{2 B_{0}}\left(\frac{w}{w_{B}}\right) J_{\alpha(1-\delta)}^{2}[\alpha(1+\delta)],
$$

$$
a=\frac{\omega}{w_{B}} \frac{r-1}{4 r} \gg 1 \text {. }
$$

In order to compare the results, conslder the case $\$=1$, for which the 8essel function can be approximated by :

$$
\mathrm{J}_{\mathrm{o}}^{2}\left[\frac{\omega}{\omega_{B}} \frac{r-1}{2 \mathrm{r}}\right]=\frac{2}{\pi} \frac{\omega_{B}}{\omega} \frac{\mathrm{r}}{\mathrm{r}-1} \cos ^{2}\left[\frac{\omega}{w_{B}} \frac{r-1}{2 r}=\frac{\pi}{4}\right] .
$$

The solution is a rapidly osctilating function with a man value of

$$
\frac{d \bar{W}}{d t}=\frac{e E_{10}^{2}}{2 B_{0}} \frac{t}{r-1} \text {, }
$$

which is Identical to equation (7) with $\delta=1$.

If a significant number of electrons airror exactly at the rebonance, it is necessary to generalize the method slightly by leaving the density inside the integral in equation (2), and by introducing a phenonenological resonance width of $v=1 / T$ where $T$ is given by equation (5). The calculated heating rate for these particles is then 


$$
\frac{d \vec{W}}{d t}=0.21 \frac{e E_{10}^{2}}{B_{0}}\left(\frac{\omega}{w_{B}}\right)^{1 / 3}\left(\frac{r}{r-1}\right)^{2 / 3} \text {. }
$$

In good agragnent $* 1$ th the result of Grawe ${ }^{6}(0=0)$ and of Guest ${ }^{3}$.

c. Application to a mogetic mirror.

Cons1der a magnetic mirror field of the form

$$
B(Z)=\frac{1}{2} B(0)\left[(R+1)-(R-1) \cos K(Z)\left(-\pi<K z^{<} \pi\right)\right.
$$

and a loss cone elactron energy digcribution given by

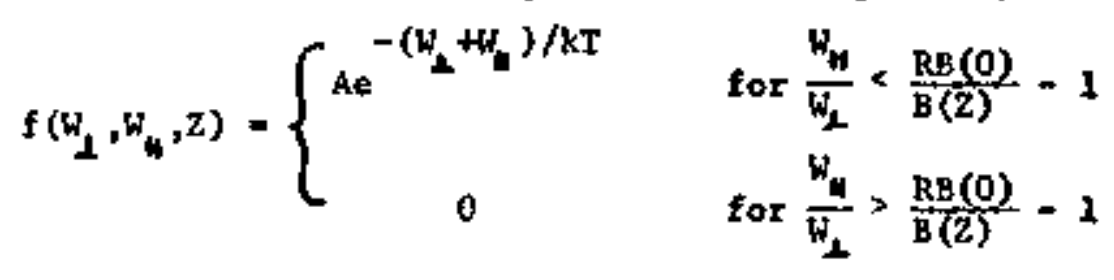

The density distribution 18 obtalned by Integration:

$$
n(z)=\int_{0}^{\infty} \int_{\frac{R(O)}{R(2)}-1}^{\infty} A w^{-W_{\perp} / k T} e^{-W_{n} / k T} d w_{\perp} d w_{w}=n(0) \frac{R B(0)-B(Z)}{(R-1)(B(0)}
$$

The cotal number of electrons in the flux shell 18

$$
\int_{0}^{\pi / K} \frac{n(z) d z}{B(z)}=\frac{\pi D(0)}{K B(0)} \frac{\sqrt{R}-1}{R-1} \text {. }
$$

Substituting into equation (4) glves a heating rate of

$$
\frac{d \bar{W}}{d t}=\frac{e E_{\perp 0}^{2}}{2 B_{0}(\sqrt{R}-1)} \sqrt{\frac{R-r}{r-1}} \text {, }
$$

where $\mathrm{I}=\mathrm{B}_{\mathrm{o}} / \mathrm{B}(0)$.

We can define a perpendiculer and parallel "temperature" at $\mathrm{Z}=0$ by

$$
k T_{\perp, \|}=\frac{A}{n(0)} \int_{0}^{\infty} \int_{\frac{W}{R-1}}^{\infty} w_{\perp, H} e^{-W_{\perp} / k T} e^{-W_{w} / k T} d w_{\perp} d w_{a}
$$

to get the result:

$$
\begin{aligned}
& k T_{\perp}=\left(\frac{R+1}{R}\right) k J \\
& k T_{\|}=\left(\frac{R-1}{R}\right) k T .
\end{aligned}
$$


We expact, therefore, a midplane anisotropy of

$$
\theta=\mathrm{T}_{\perp} / \mathrm{T}_{w}=\frac{\mathrm{R}+1}{\mathrm{R}-1}
$$

The heating rate for an arbitrary andsotropy can be calculated in a straightforward way by generaltzing the assuned distribution function, but the resulting equation is qufte complicated and unenlightening. Qualitatively, a large anisotropy enhances the heating if resonance occurs near the midplane and reduces the heating for resonance near the mirror throats.

Electrostatic potential gradlents can also be Included in the nodel by simply addsing a Boltzanan factor, $\exp (-\mathrm{e}(2) / k T)$ to the density distribution in equation (9).

D. Limitations and discussion.

The use of a steady state, cold plasa conductivity to calculate the heating rate is justifled if

$$
\omega>\nu=\frac{1}{T}-\sqrt{\frac{v_{u} 0^{\omega}\left|\nabla_{0} O^{B}\right|}{\mathrm{B}_{0}}},
$$

or

$$
v_{\text {no }} \ll \omega \mathrm{B}_{\mathrm{o}} /\left|\nabla_{\mathrm{Mo}} \mathrm{B}\right|
$$

Th1s condition is generally well satiafled for non-relativistic plasmas in typical magnetic fleld geonecries.

Calculation of the heating rate requires a knowledge of the electric fleld $\mathrm{E}_{10}$. The vacuum electric fleld is perturbed locally ot waw because of the resonance in the dielectric constant, which in the absence of collistons can be written as

$$
E=\varepsilon_{o}\left[1-\frac{\omega_{p}^{2}}{w\left(w-w_{c}\right)}\right]
$$

This local percurbation is negligible provided

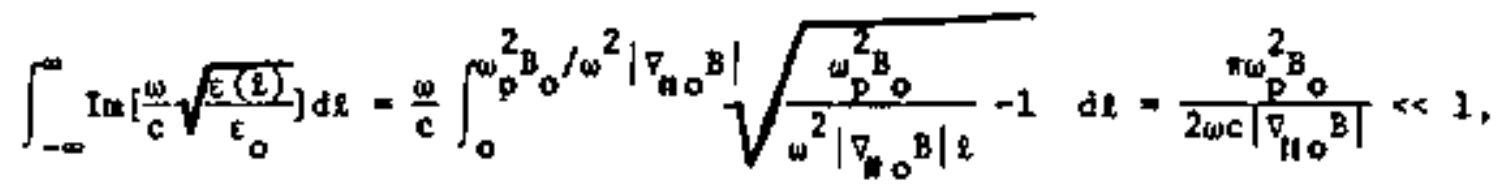


or $\omega_{p}^{2} \ll \omega c \mid \nabla_{11} \mathrm{~B} / / \mathrm{B}_{0}$.

The low denstcy plasmas produced by electron cyclotron heating generally satisfy this requirement.

In addition to this local perturbation, the nean square electric field In the cavicy is reduced because the cavity $Q$ is lowered in the presence of plasma. The tnput powet $P_{0} 18$ given by

$$
g_{0}=\frac{\omega E \bar{E}^{2} v}{Q_{0}} \div \int \frac{d P}{d \psi} d \psi,
$$

where the first term on the right if the power absorbed by the cavity and the second term is the power absorbed by the plasms. The second terw can be written, according to equation (3), as

$$
\int \frac{d P}{d \psi} d \psi=\frac{\overline{n e E^{2}} v G}{B_{o}},
$$

where

$$
G=\frac{\pi}{2 V} \int \frac{n_{0}}{\pi} \frac{E_{10}^{2}}{\pi^{2}} \frac{d \psi}{\left|\nabla_{0}^{B}\right|}
$$

15 a factor of order unity that dependa on the geonetry of the field and denstey distribution. For n-const and $\mathrm{E}_{20}^{2}=\frac{2}{3} \overline{\mathrm{E}^{2}}$, we have

$$
G=\left.\frac{\pi}{3} \frac{\mathrm{B}}{\mathrm{V}} \frac{\mathrm{dV}}{\mathrm{dB}}\right|_{\mathrm{B}_{\mathrm{O}}} .
$$

The wean aquare electric fleld in the preaence of plasma is given by

$$
\overline{E^{2}}=\frac{P_{o}}{\frac{\Delta E_{0} V}{Q_{0}}+\frac{\bar{n}+V G}{B_{0}}} .
$$

and the resulting heating efficlency is

$$
n=\frac{1}{\mathrm{P}_{0}} \int \frac{\mathrm{dP}}{\mathrm{d} \psi} \mathrm{d \psi}=\frac{1}{1+\mathrm{n}_{\mathrm{c}} / \bar{n}_{\mathrm{o}} \mathrm{G}},
$$


where $n_{c}=\varepsilon_{o} a^{2} / e^{2}$. Hote that at low densities, the efficlency is proportlonal to density, but for $\bar{n}>n_{c} / Q_{0} G$, the plasma loading dominates the cavity Q, and total absorption of the rf is expected. At much higher densities ( $\left.{ }^{>} \mathrm{p}_{c}\right)$, the rf flelds are excluded from the plasna, and the efficiency presumably decreasea . 


\section{Reference:}

1. T. Kawamura and $Y$. Teradh1ma, in Institute of Plasne Physics, Nagoys University Annusl Review, page 203 (1968).

2. A. J. Lichtenberg, M. J. Schwartz, and D. T. Tuna, Plasna Physefcs 11 , 101 (1969).

3. G. E. Guest, In Oak Rfdge National Laboratory report ORNL-4150 (1967), page 29.

4. W. B. Ard, in Oak Ridge National Laboratory report ORNL-4401 (1968), page 41 .

S. A. F. Kuckes, P1asme Phystes 10, 367 (1967).

6. H. Grave, Plasma Phyoles 11, 151 (1969). 


\section{CONPUTER SDUUEATION}

\section{J. L. Shohet}

The work reported in this section is the result of an effort to gimulate the electron cyclotron heating of a plasma on a computer. 1 The model used is collisionless but the self-conststent electric fleld of the "super-perticles" making up the piaswa is calculated and used, along with an axternal rf electric fleld and a de nagnetic field. The particles are given a Maxwellian veloc1ty distribution and their nass is relativistically changed through each tine gtep.

A bastc description of the nethod used has been presented previously. The basic problew solved is the following: the plasma 1a placed in a 2-dimenstonal rectangular plane in which the magnetic fleld is perpendicular and untform to the plane. 900 super electrons and 900 super-Ions are placed uniformly in the plane in one of two ways. These are: a) electrons alternated positlons with lons, b) electrons and lons have the "same" coordinates Intially. The following 1 teng further specify the problew.

\begin{tabular}{|c|c|}
\hline $\begin{array}{l}\text { Number of real particles per } \\
\text { "super particle" }\end{array}$ & $10^{10}$ \\
\hline rf heating frequency & $8.39 \times 10^{9}+\mathrm{Hz}$ \\
\hline Electron cyclotron frequency & $8.39 \times 10^{9} \mathrm{~Hz}$ \\
\hline Electron plasma. frequency & $2.7 \times 10^{8} \mathrm{~Hz}$ \\
\hline Electron density & $3.62 \times 10^{14} / \mathrm{m}^{3}=3.62 \times 10^{8} \mathrm{~cm}^{3}$ \\
\hline Electron temperature (1nit1el) & 10 electron voles \\
\hline Electron Debye length (1n1tially) & $1.23 \times 10^{-3}$ meters $=1.23 \mathrm{~mm}$ \\
\hline Dimenston of plane & .16 meters = $160 \mathrm{~nm}$ \\
\hline dc magoetic fteld & 3000 gauss \\
\hline
\end{tabular}

The t1me step is always 1/20th of the shortest perfod, be it cyclocron, plasma, or rf excitation (the latter if off regonance heating ta desired). 
For this problen, the shortest pertod ts the cyclotron period. At each time step the kinetic energy of the electrons and lons is computed, as well as the electrostacic energy stored in the region of interest. A photographic record. of the positions of the electrons and lons is also nade at each point.

Several Interesting results appeared. They are: 1) there is heating of the fong as well as the electrons. This 1 s bastcally due to the space charge fleld of the electrons; 2) the kinetic energy increases rapidly without the need for collistons; 3 ) the electron cyclotion inotability has beet observed after the heating ffeld has been turned off. A discussion of this will follow at the end of this section.

Figure 1 shows the kinetic energy of the electrons and fons as a function of time. Note that the heating race may be easly evaluated from these data. However, to ascertaln whether true heating has occurred, it is necessary to Invegtgate the velocity distribution after heating. If It looks Kaxwellian, then heating has occurred. Figure 2 shows the electron velocity distribution after $51 / 2$ hesting sycles (120 tine steps). A 10 electron volt and a 160 electron volt Maxwellian are also plotted on the same curve. The latter function was used because 160 electron volts is the computed electron temperature at the end of the pulses.

Figure 3 shows the electric fleld in the $x$ direction at a point in the middle of the left quadrant of the interaction reglon. In this case the masa of tons was made only 5 thmes greater than that of the electrons. This was done to show the effects of the fon motion nore quickly. This graph shows osctilation of the electrfic fleld at both the electron and ton cyclotron frequencles. When the heating is removed, after 110 clne steps, the oscillations continue but grow in amplitude. The growth rate may be calculated. It is, in effect, an fnstability, similar in form to that produced 


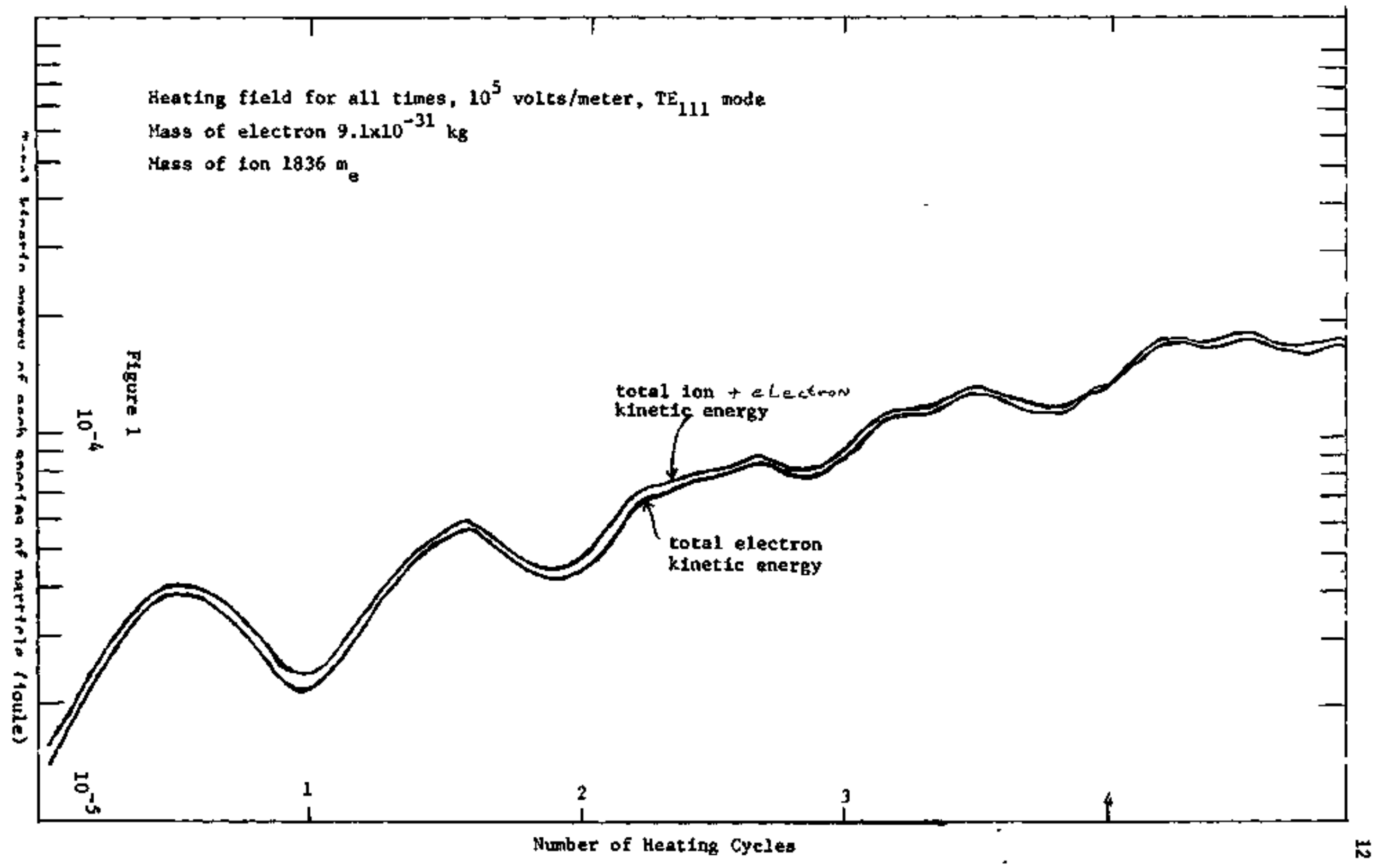




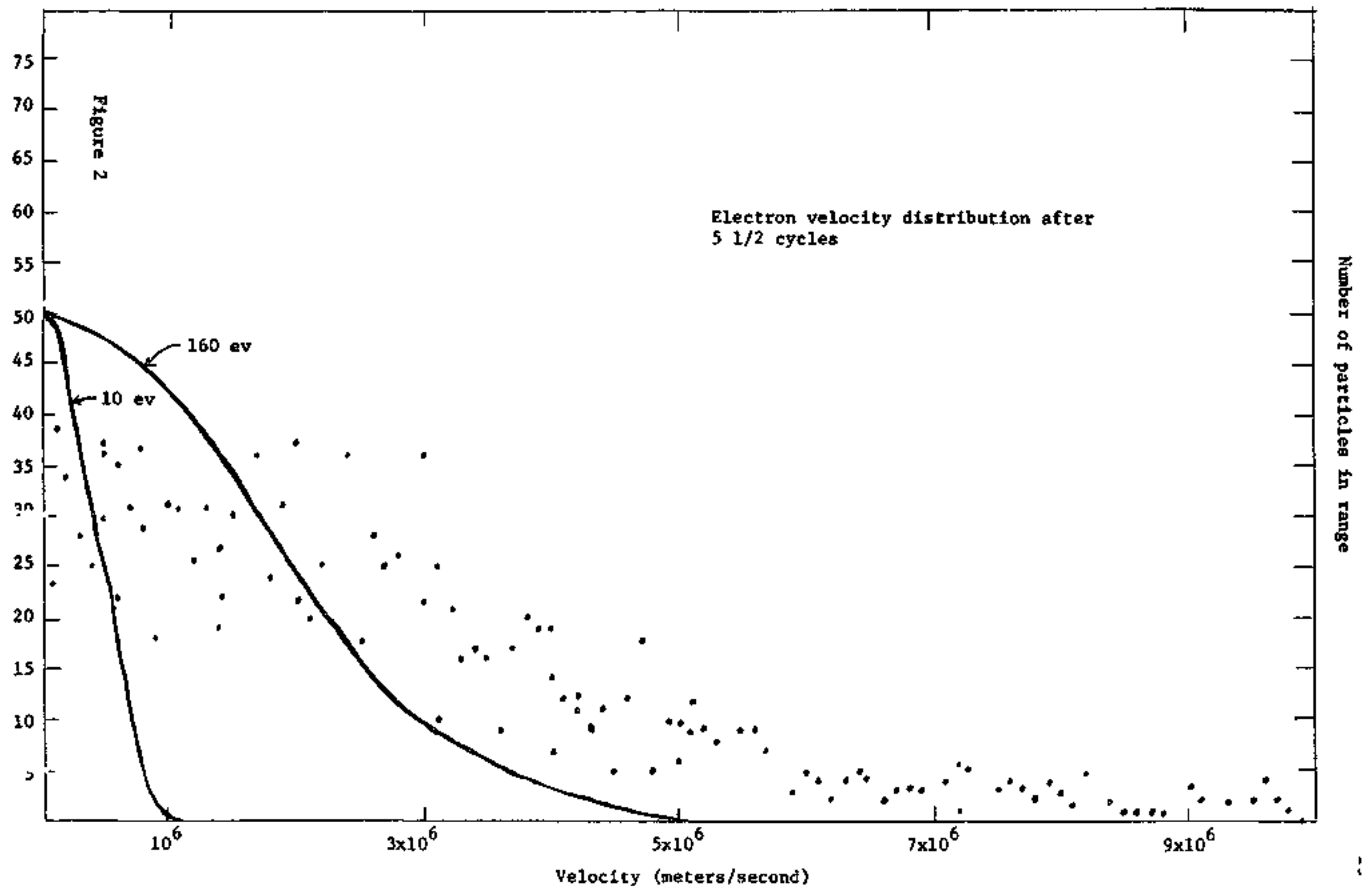




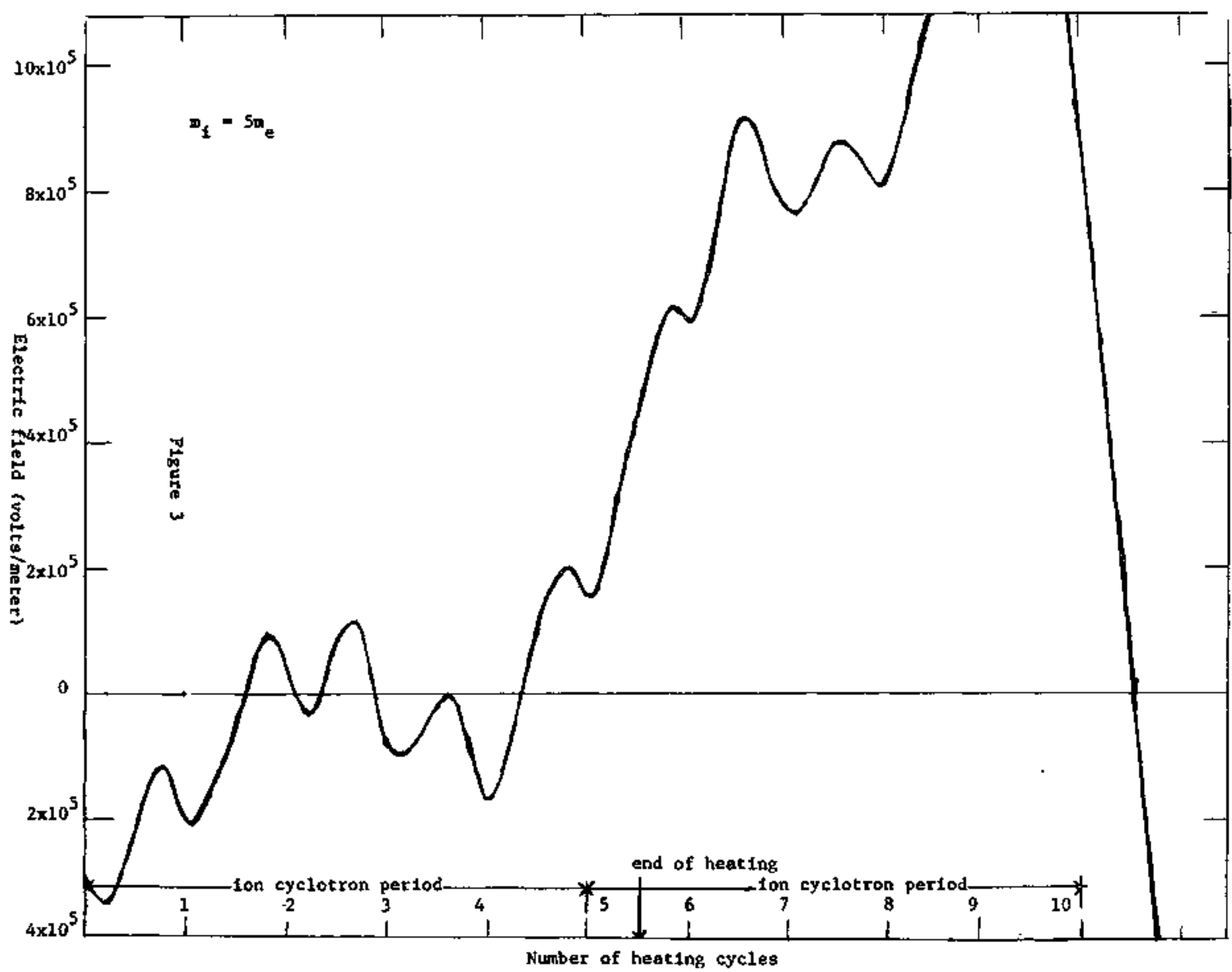


in the actual experinent. Figure 4 shows the kinetic energles of the electrons and lons for this probler.

To andyze thls Instability we note the "experimental" conditions.

There is no motion in the direction perpendicular to the resonance plane, 1.e., Infintte antsotropy. There are no collisions. Under these conditions the electron cyclotron instability w11l appear, if enough particles are woving in phase (the result of the heating process) at the electron cyclotron frequency. The growth rate of the instability has been found to be

$$
\frac{{ }_{\mathrm{p}}}{\sqrt{2}} \frac{\left\langle v_{\mathrm{T}}\right\rangle}{\mathrm{c}}
$$

and agrees excellently with the growth rate measured from the computer.

The experimental measurements also show a siallar result. The anisotropy in the real experinene has now been show to be quite high. The coliiston rate is low, and under these conditions, the frequency of the instability is predicted to be, and $\underline{\text { is, }}$ less than the electron cyclotron frequency and Its growth rate is also alighty less than that shown here.

Note alao, that the growth rate is Independent of the nagnetic field. The computer atmulation was tested for this relation by doubling the magnetic f1eld. No change in the growth rate was observed, When the number of particles per super particle were lowered by a factor of 100 (to lower the plagma frequency by a factor of 10 ) the growth rate was observed to drop to, the appropriate level.

The value of $\left\langle\mathrm{v}_{T}\right\rangle$ used in calculating the growth rate 1 s the average at the time at wilcin the rate 1s meabured to correct for the effects of the heating.

Figure 5 shows the initial positions of the electrons and tons. The electrons are represented by the symbol $M$ and the lons by the aymbol $*$. 


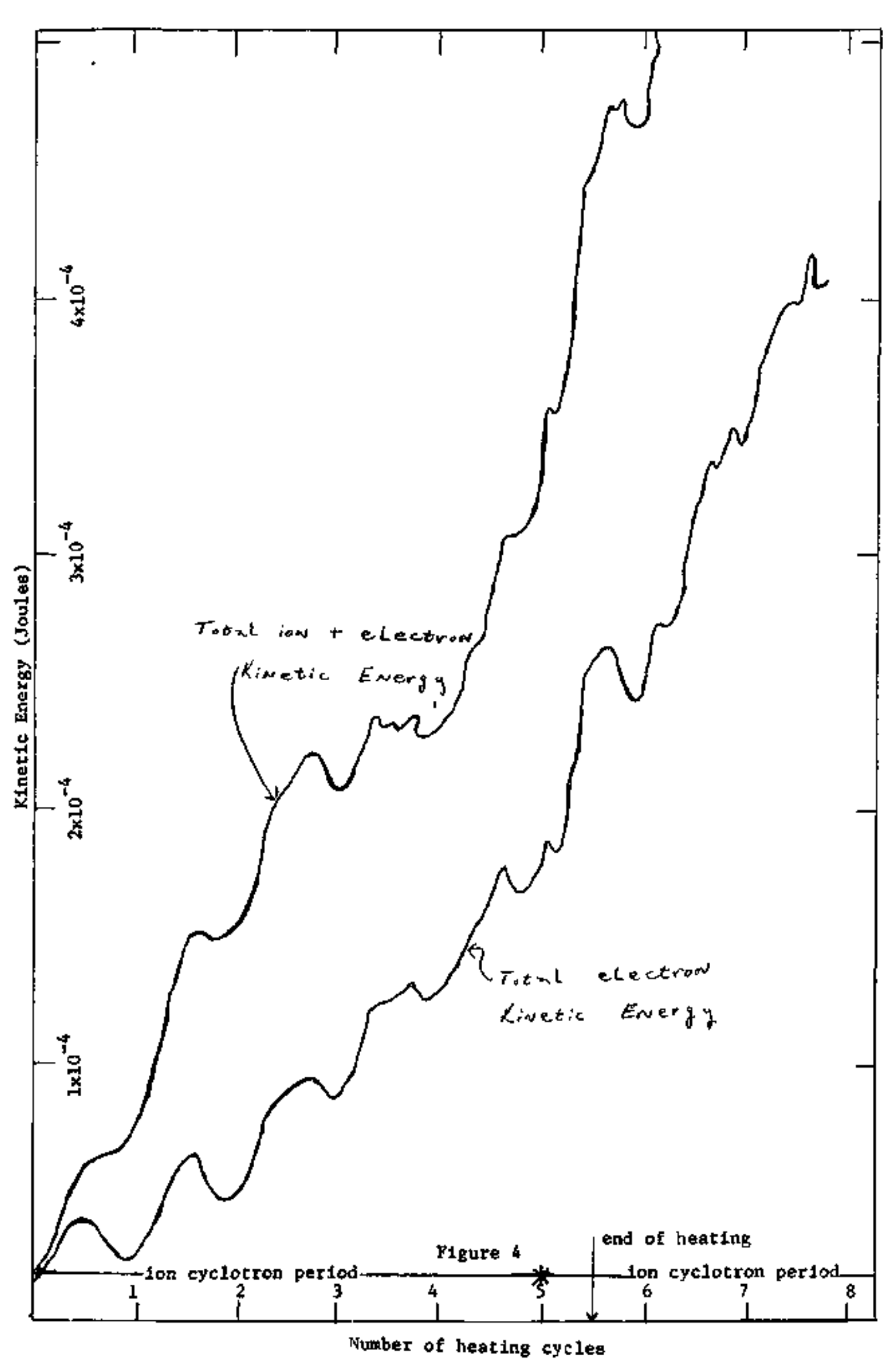




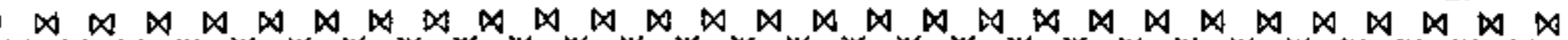

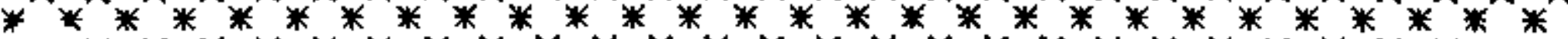

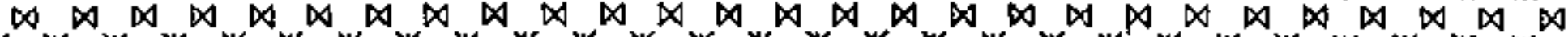

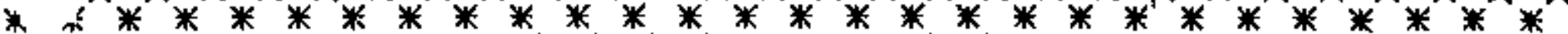

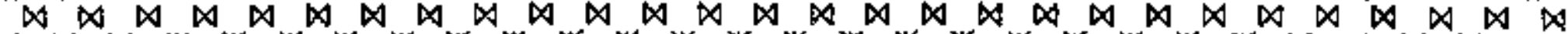

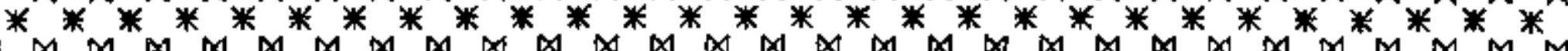

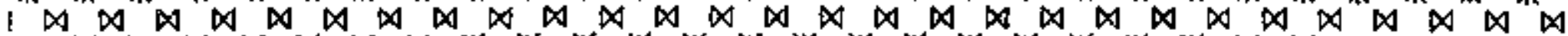

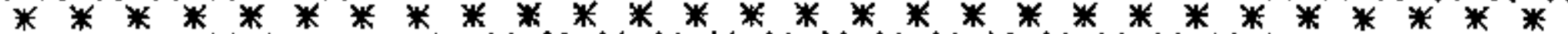

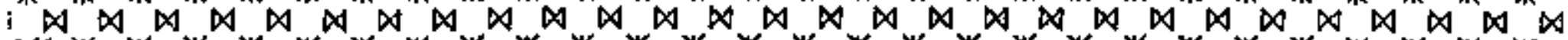

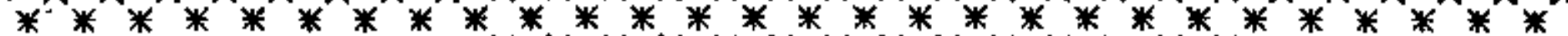

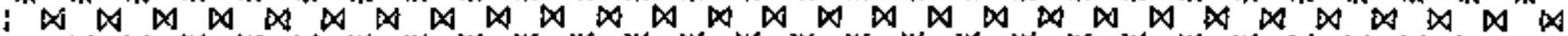

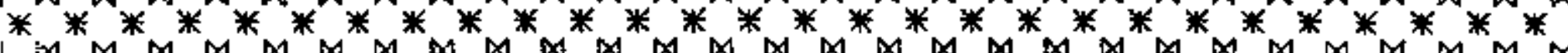

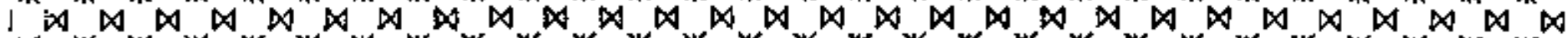

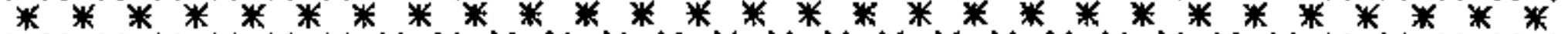

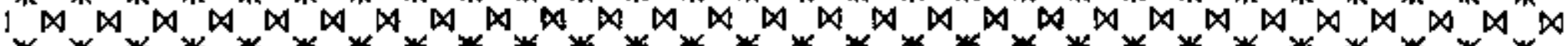

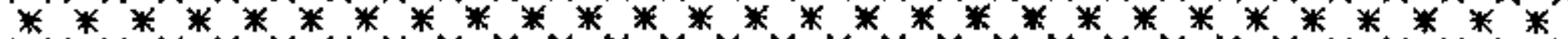

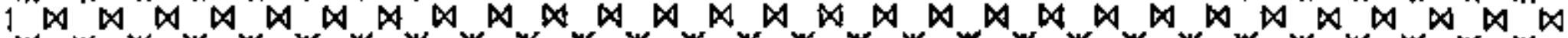

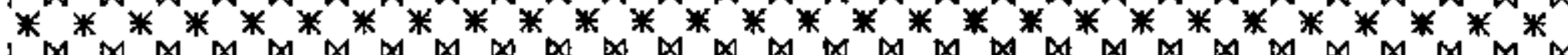

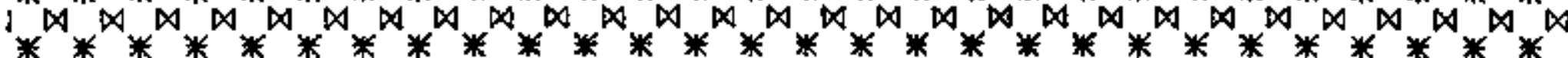

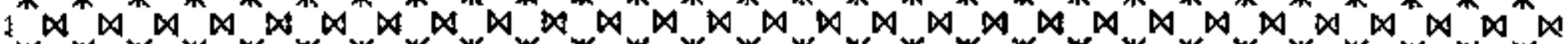

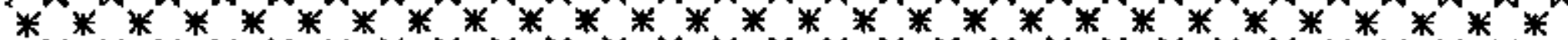

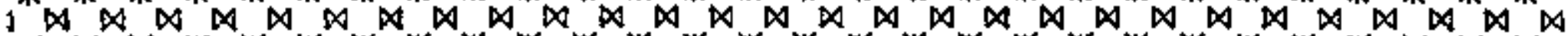

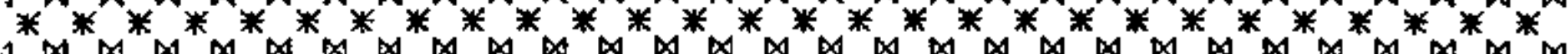

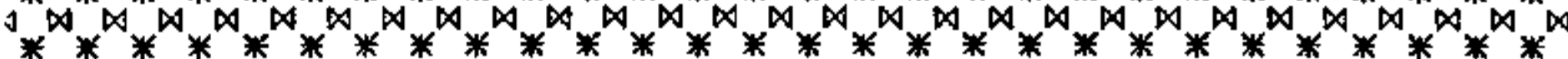

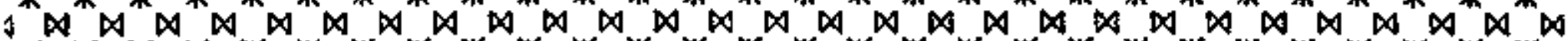

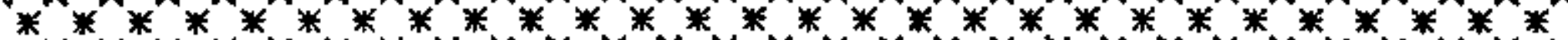

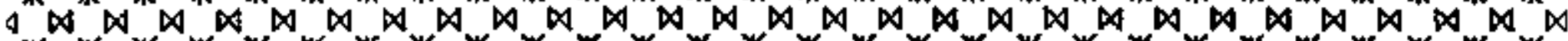

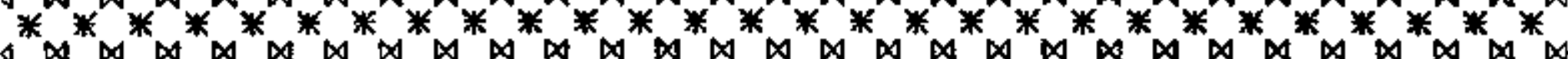

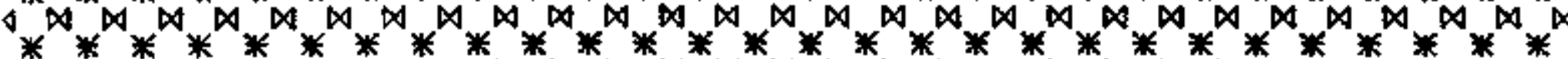

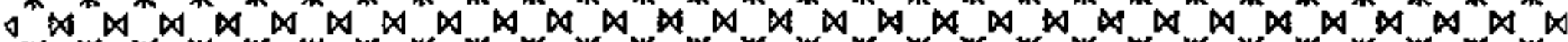

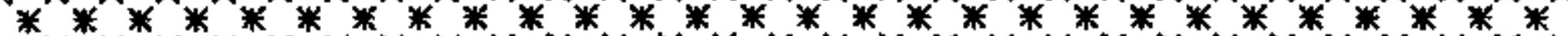

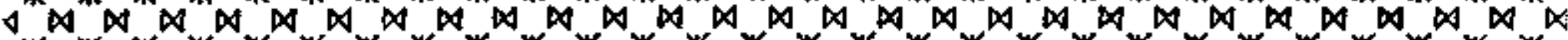

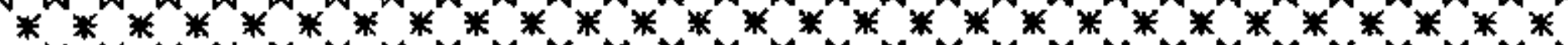

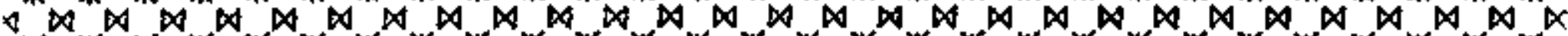

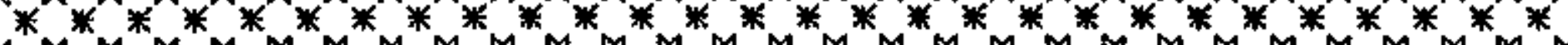

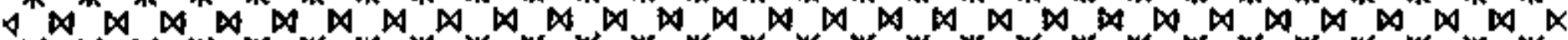

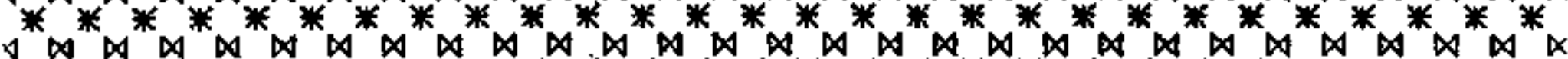

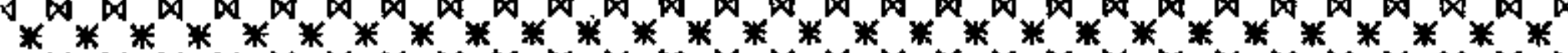

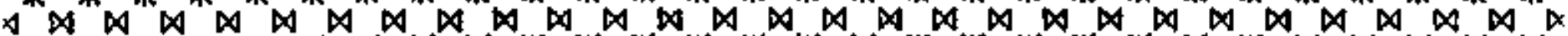

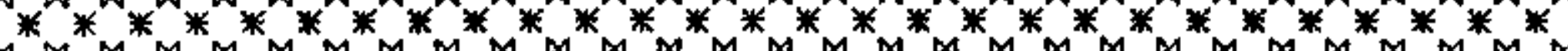

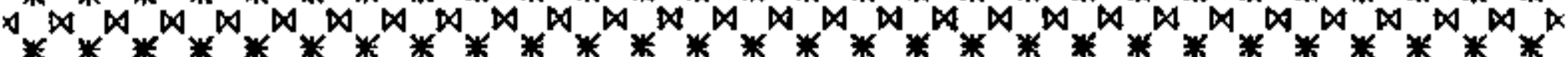

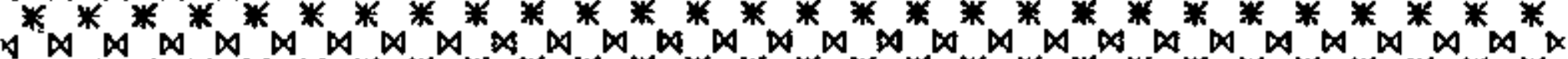

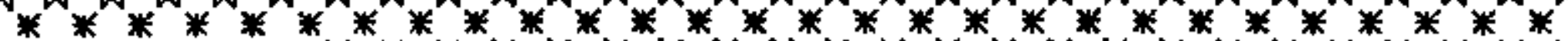

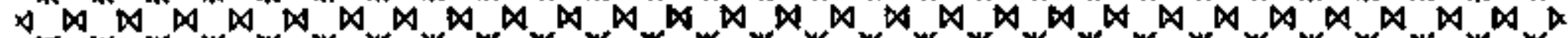

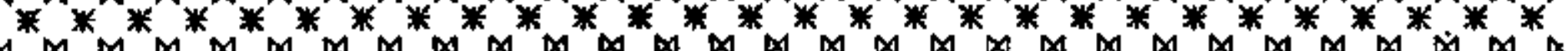

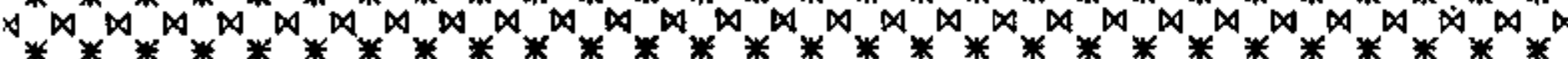

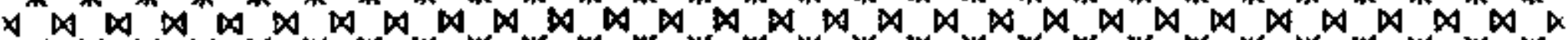

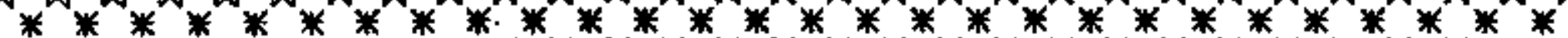

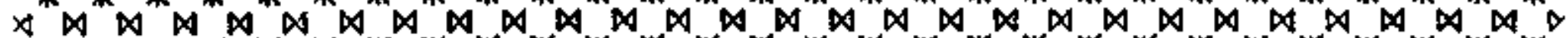

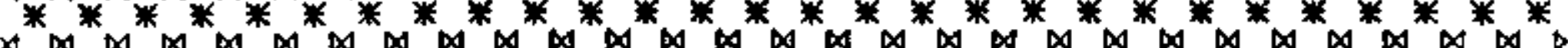

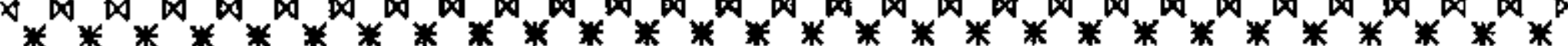

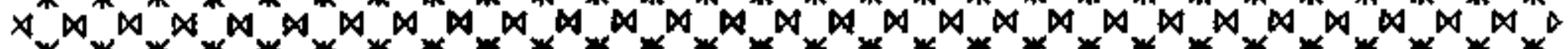


Figure 6 shows the positions after $51 / 2$ heating cycles, and Figure 7 shows the result of $51 / 2$ cycles after the heating pulae is turned off. Both of these are for the case where the fon masa 185 times the electron wass. When the ions are allowed to have their correct mass, there 18 essentially no change In position detected.

It should be noted that there if very little difference in the results between the two possible starting positions, 1.e., electrons on top of Ions, or electrons alternating with lons. The latter condition results in somewhat greater heating rates since the oelf-consiatent field is not zero at time=0 In this mode1.

The program is also belng used to check for $x f$ confinenent. ${ }^{2}$ In this case, the dic magnetic fieid is set to zero, and the particles are noved with the self-consistent field and the rf electric and magnetic flelds. The electric fleld amplitude ts set to s000 volts per meter. Figure 8 shows the positions of the lons and electrons after 44 heating cycles. The lons have their full mass fn this problen. Sone slight evidence of confinement is noticed in the center regfon. However, it is quite weak and much more computer tipe will be needed to show the result. 


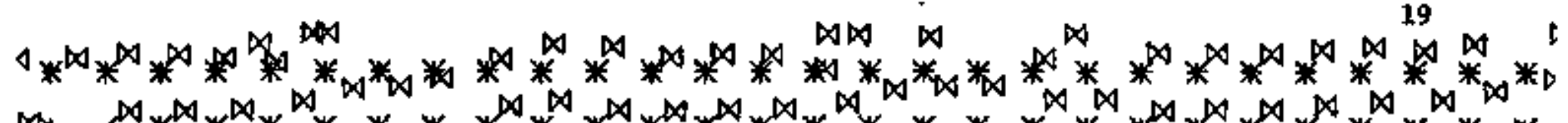

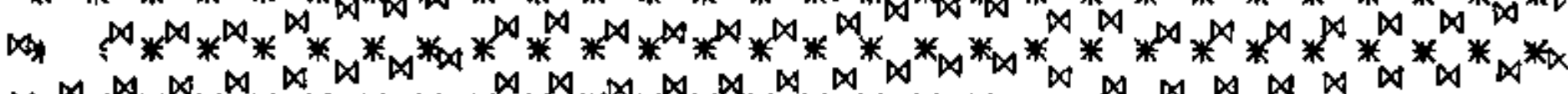

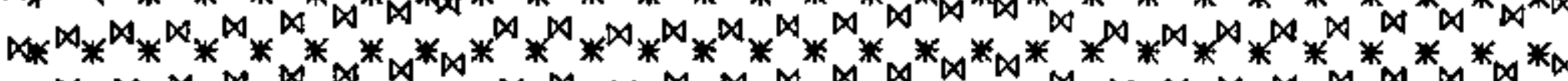

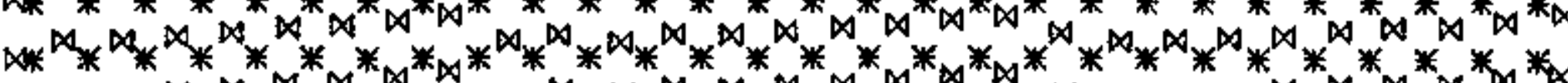
め..

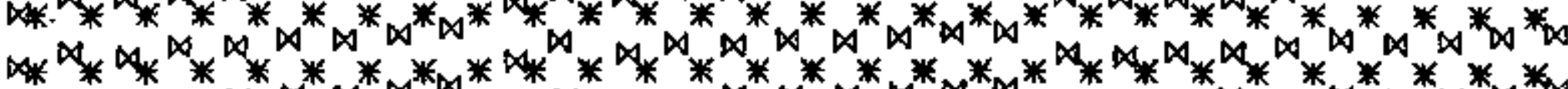

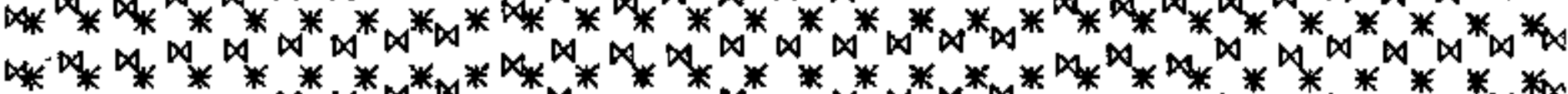

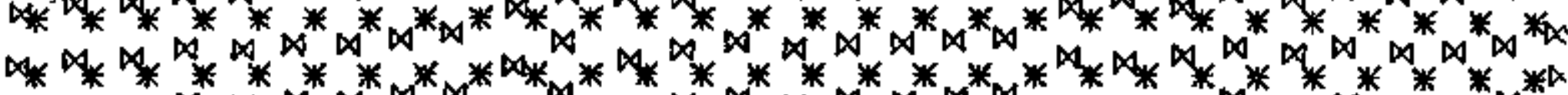

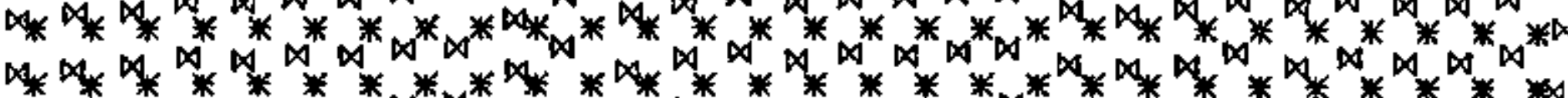

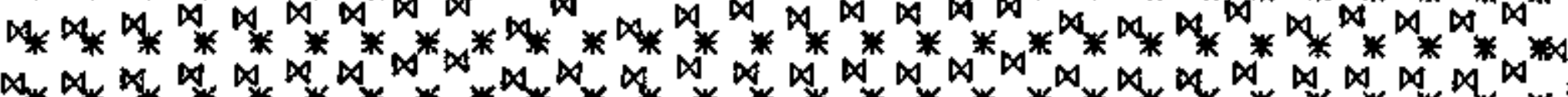

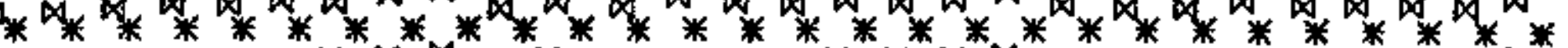

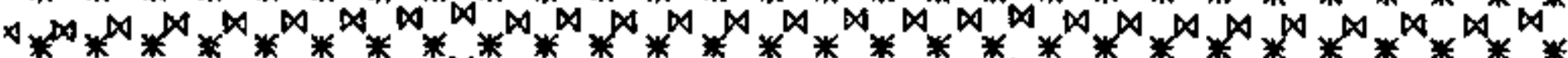

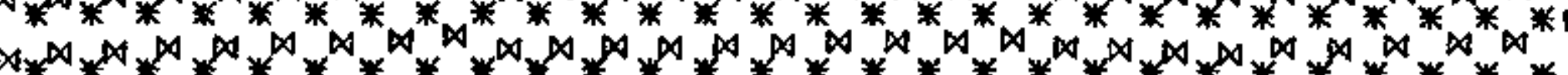

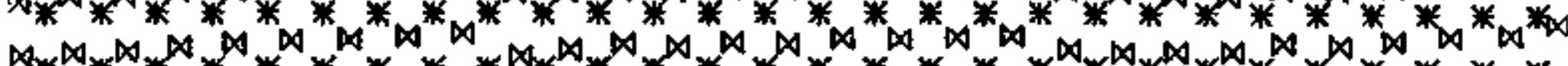

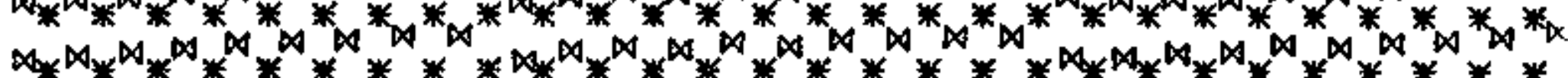

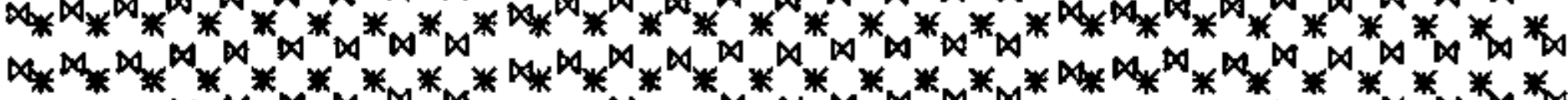

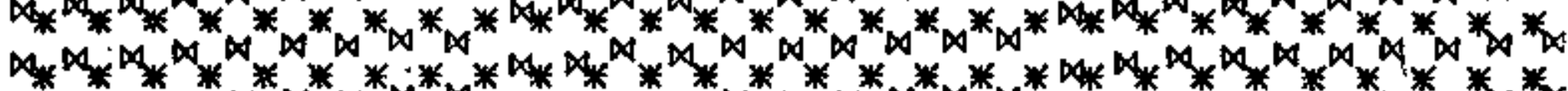

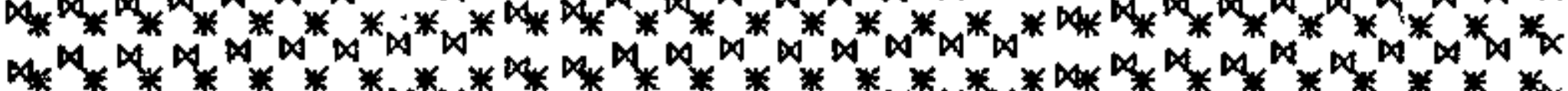

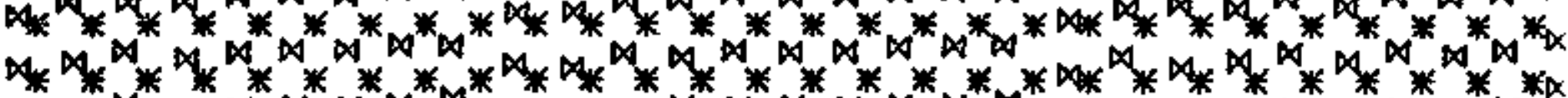

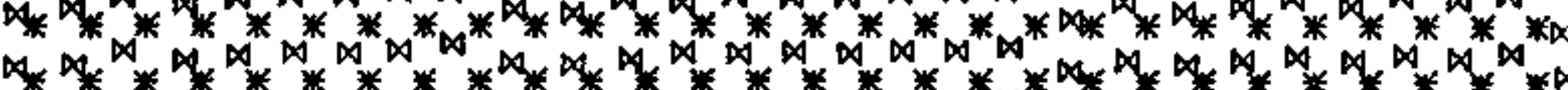

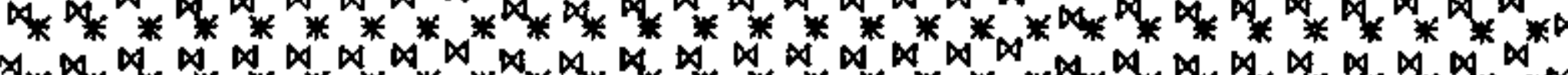

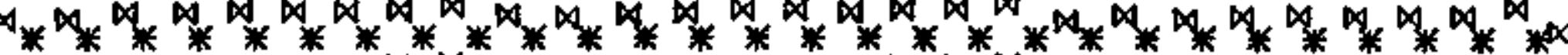

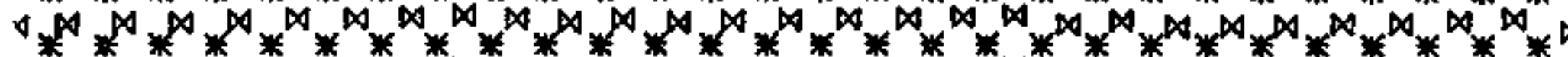

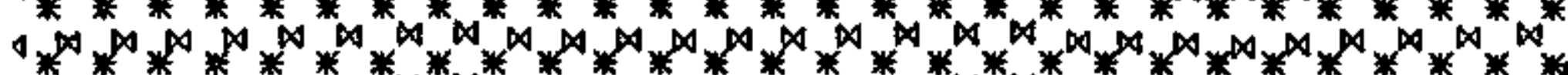

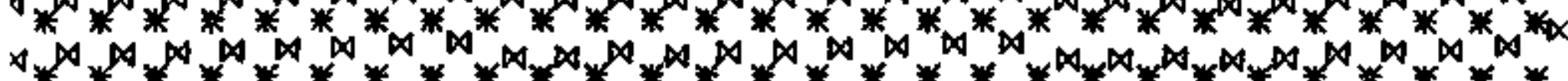

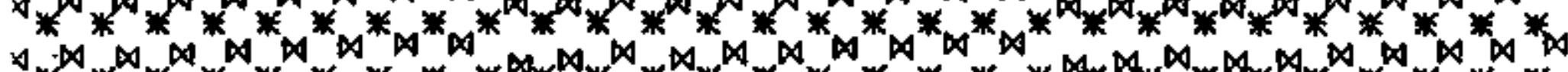

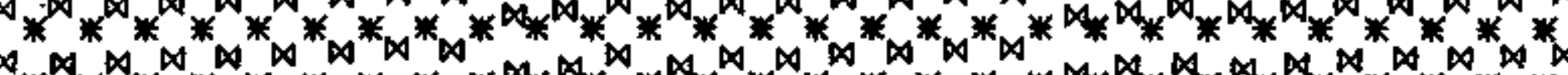

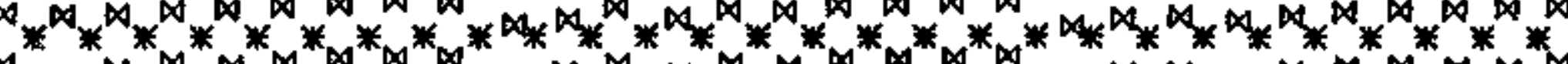

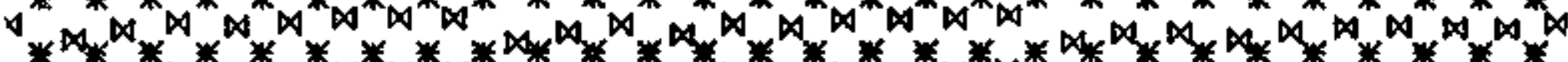

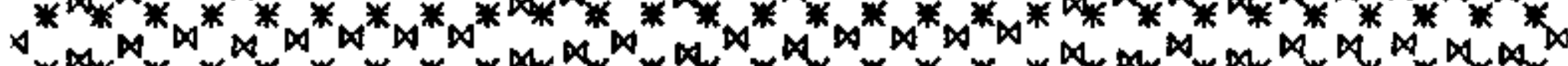

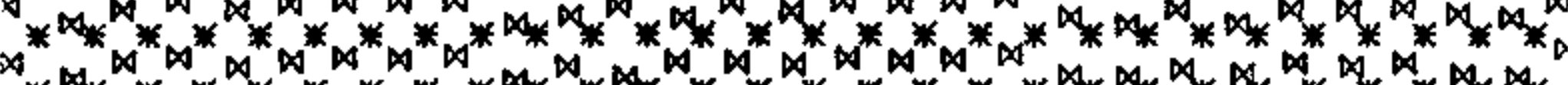

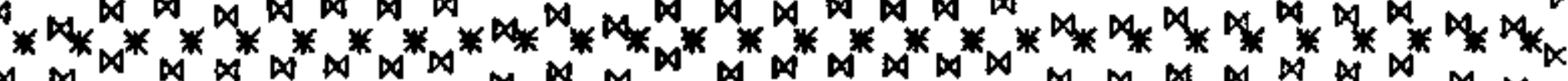

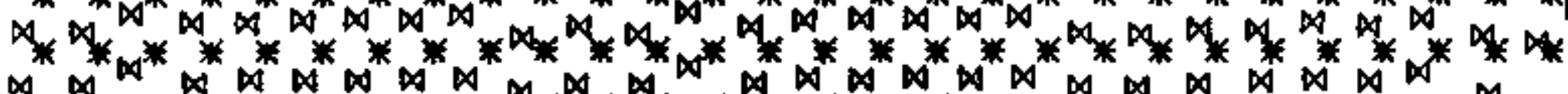
味 
* *

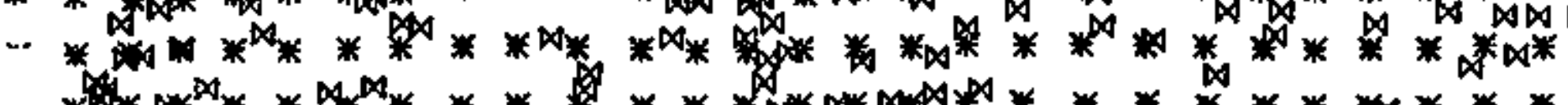

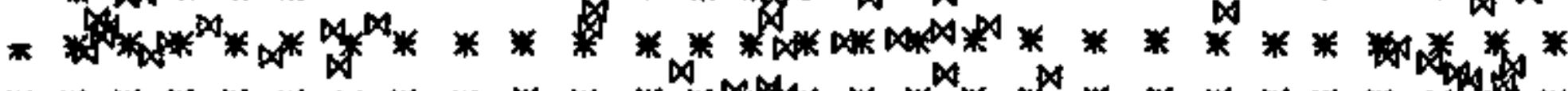

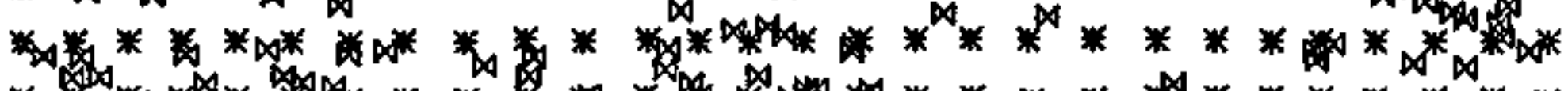

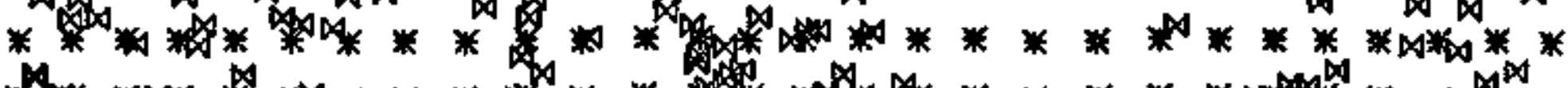

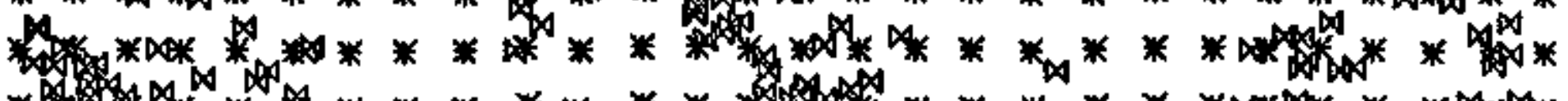
* *

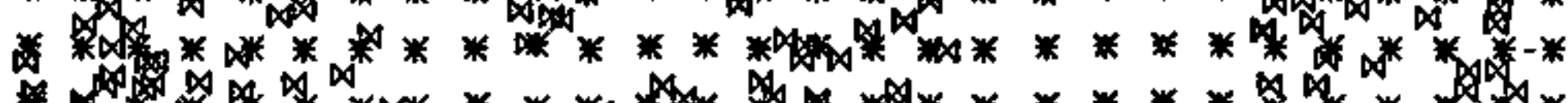

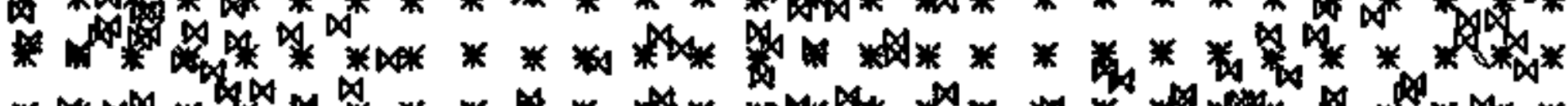
弗

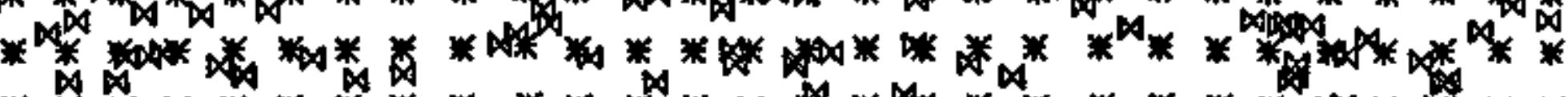

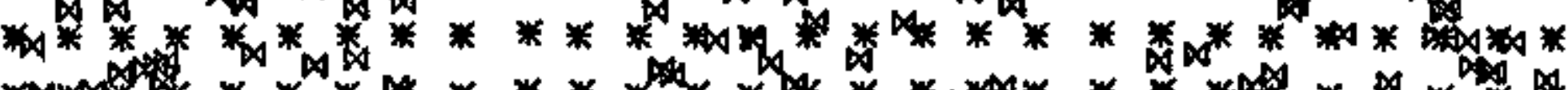

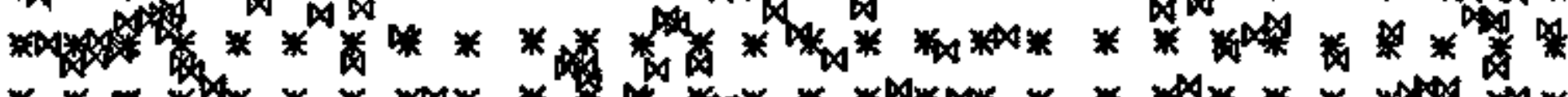

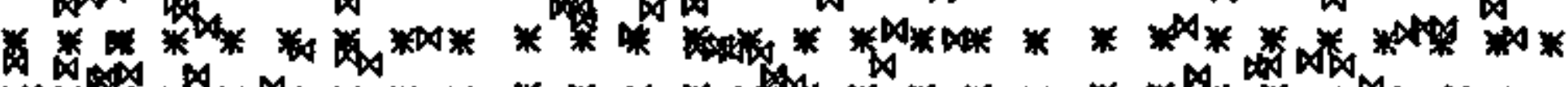
\%

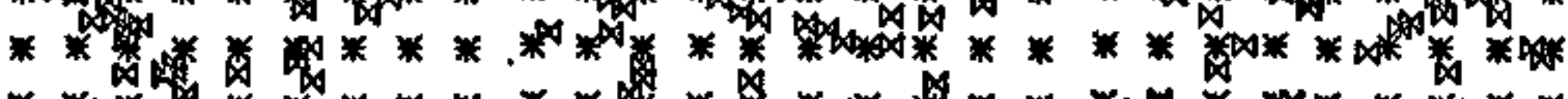
*

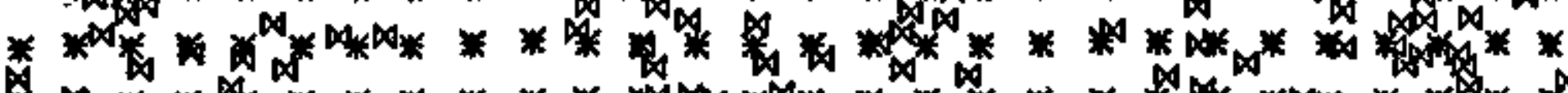

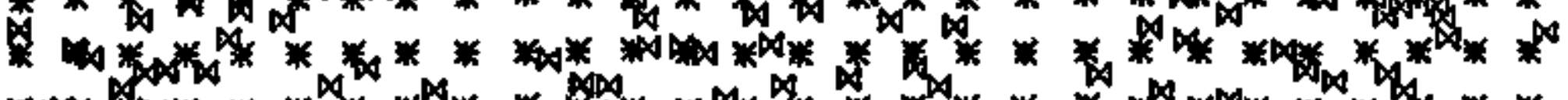
waw \% 等

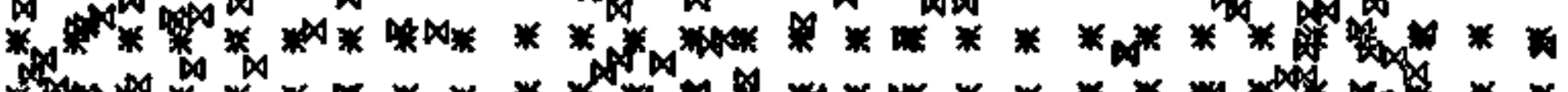

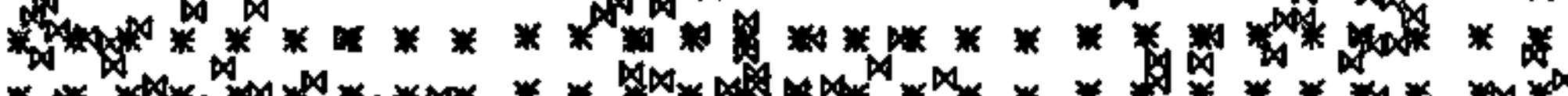
落

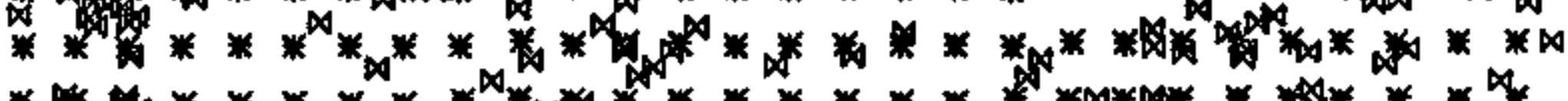
*

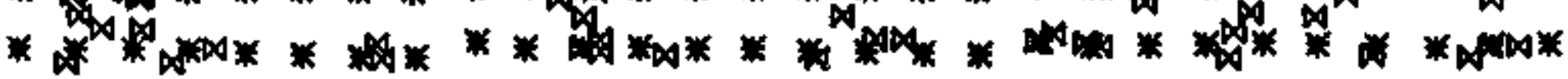




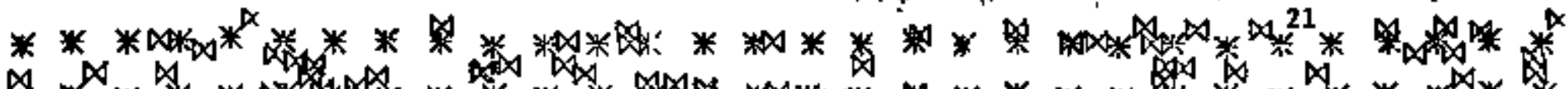

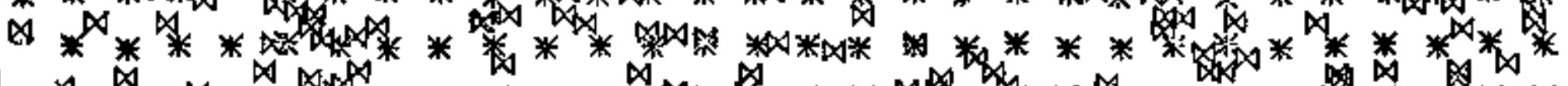

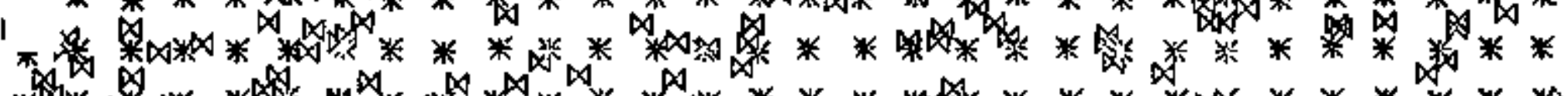

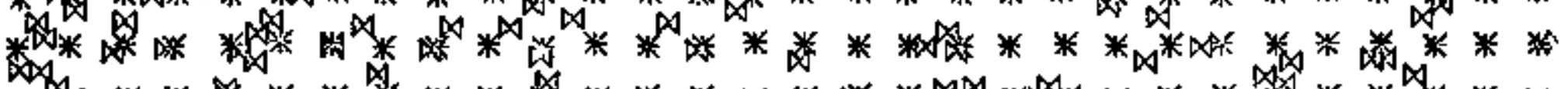

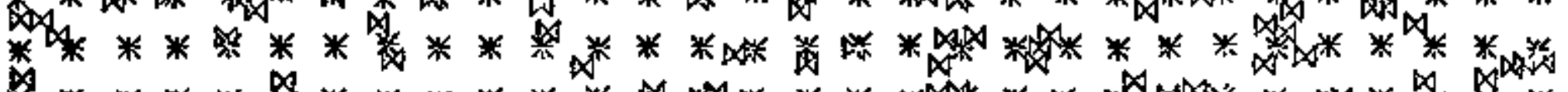

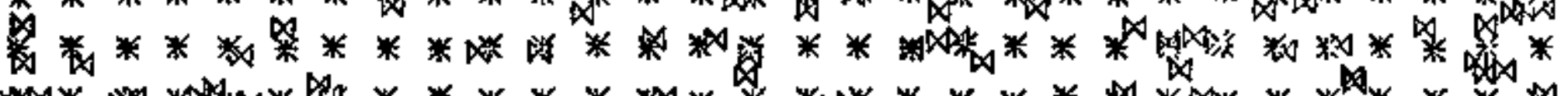

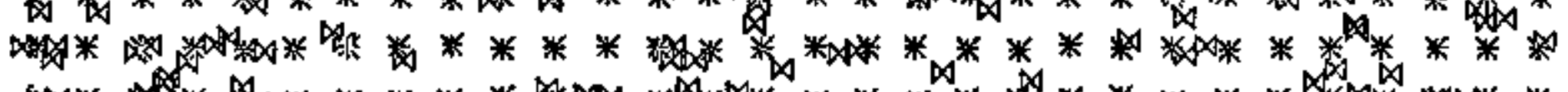

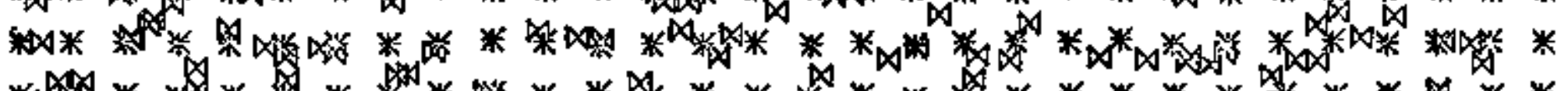

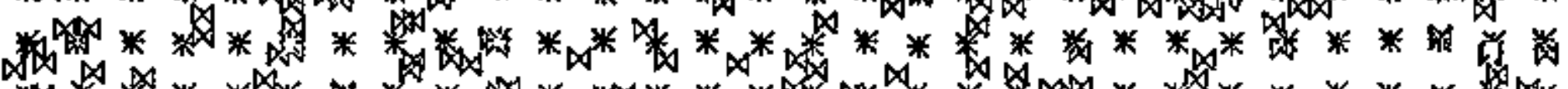

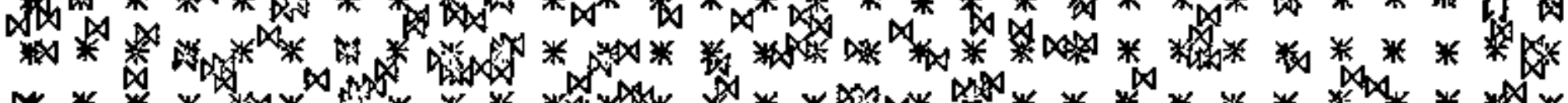

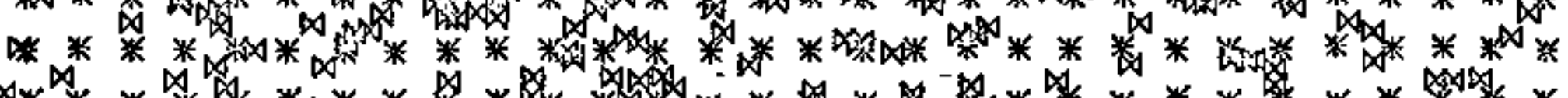

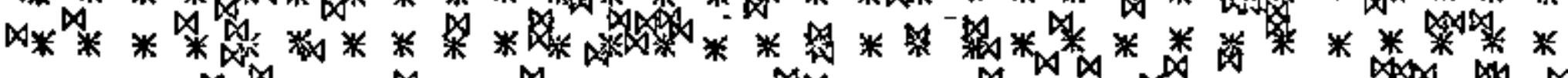

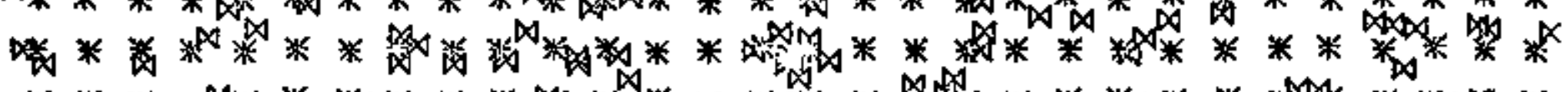

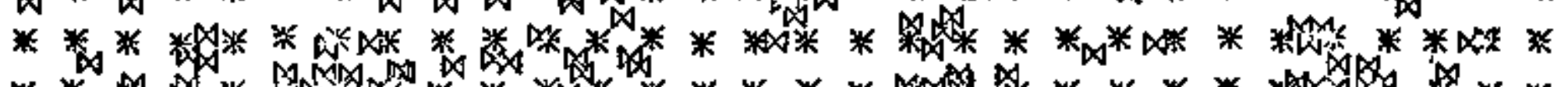

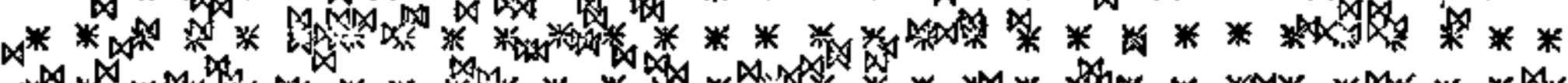

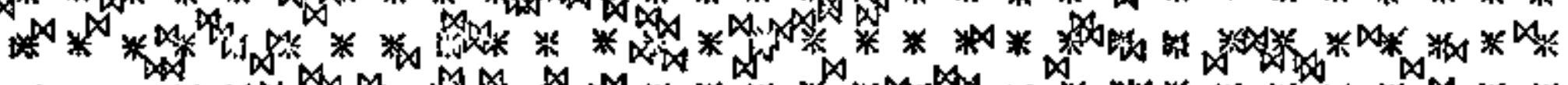

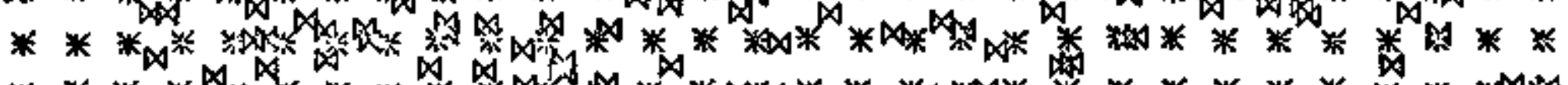

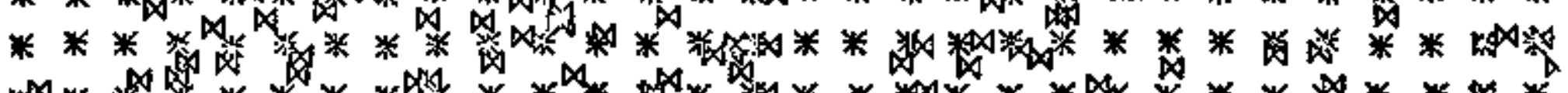

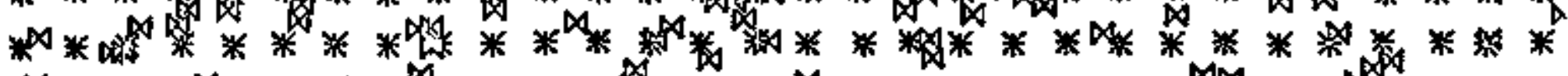

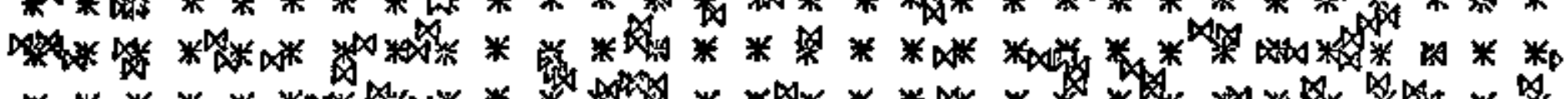

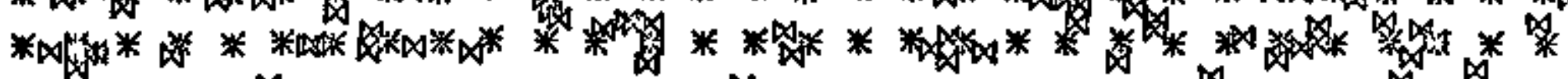

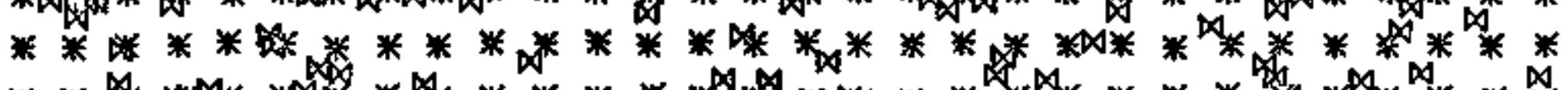

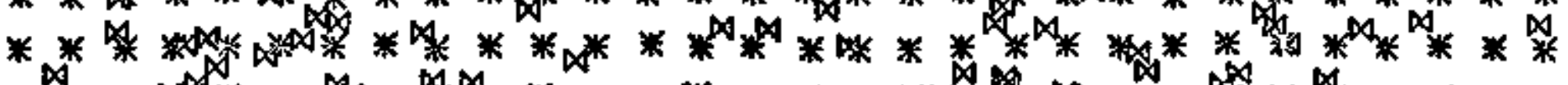

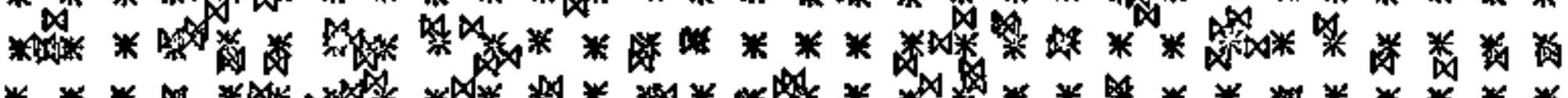

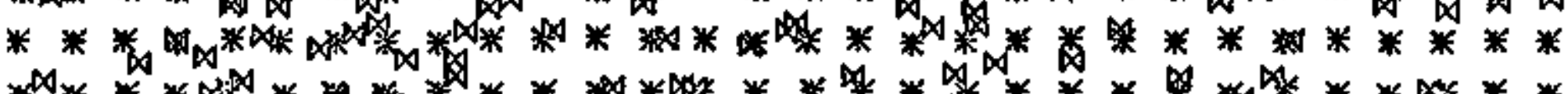

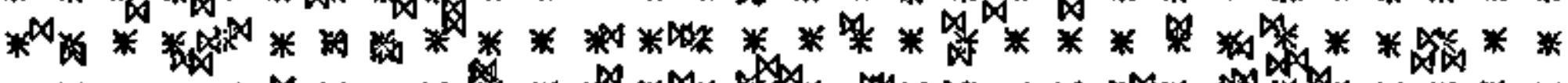

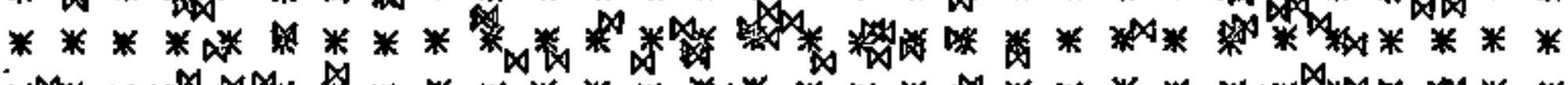

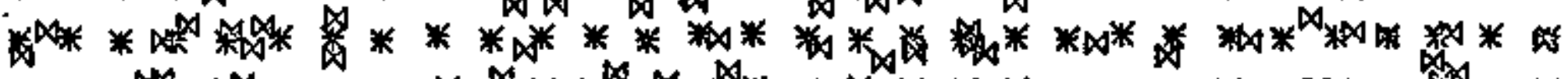

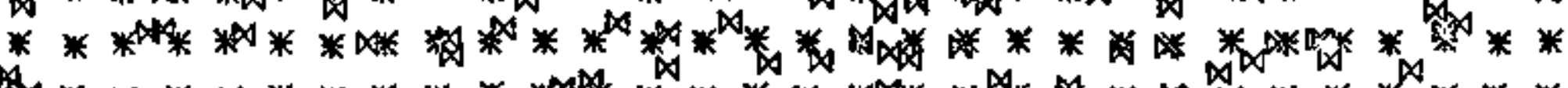

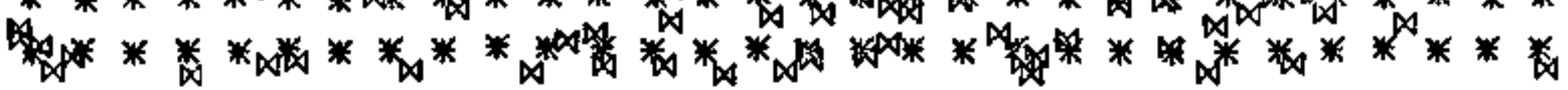




\section{References}

1. The computer used 18 a CDC 6600 located at the Centre d'Etudes Nucleatres, in Saclay, France.

2. This work was done fn conjunction with A, J. Hatch at the Argonne National Laboratory 
IV. THEORETICAL CALCULATIONS OF THE FREE-FREE BREMSSTRAHLUNG FROM AN ANISOTROPIC PLASHA

D. G. S. Greene

Two problena related to fref-free brensstrahlung from a plasma contalning relativistic electrons have been considered: 1) polartaation of the bremsstrahlung, and 2) corrections to the bremstrahlung spectra due to the finite mass of the nucleus. Both probtems were programed for sirultaneous computer calculation.

To express the polarization, the cross-section for bremsstrahtung is derived following the technique of $\mathrm{W}$. Heitler without averaging over the final gtates of polarization. These two final gtates of polariagtion yield two cross-sections: $\sigma_{1}$ and $\sigma_{2}$. Brensatrahlung emfsgion perpendicular to the magnetic field results frow $\sigma_{1} \omega_{2}$ and $\sigma_{2}{ }^{-\sigma_{\theta}}$ and has the Intensitiea:

$$
I_{z}=\int I_{0} d N v_{0} d \sigma_{z} \text { and } I_{\theta}=\int I_{0} d N v_{0} d \sigma_{\theta}
$$

where: $I_{z}=$ Intensicy of radfation polarized in the $z$ direction,

$I_{\theta}$ - Intensity of radiation polarized in the direction,

$I_{0}$ * conateant of proportlonality, and

$d N=$ density of incident electrons having velocity $v_{0}$.

The polarization 1s:

$$
P(h v)=\left(I_{z}+I_{0}\right) /\left(I_{z}+I_{\theta}\right)
$$

Preliminary approximate calculations Indicate that $P$ may be a measurable fraction.

The finite mass correction results from four considerations: 1 ) the density of final energy statee for photon and electron is altered by the final energy states for the nucleus; 2) the probobility of populating these final energy states of the nucleus is a product of the nuclear wave functions; 
3) on deriving the Heitler cross-section the incident electron energy no longer equals the recotl electron energy plus the photon energy, so certafn cancellations are no longer posslble, resulting in additional terns; and 4) the energy of the recoll electron ts less by the amount of energy taken by the recoll nucleus. For the range of energles examined (electrons up to $1 \mathrm{MeV}$ and photons up to $80 \mathrm{Kev}$ ) these effects for a hellum nucleus produce corrections to the cross-section of the order of .01\%. Moreover, the corrections are largest where the cross section is arallegt.

\section{Reference}

1. W. Heitler, Quantum Theory of Radiation, 3rd edition (Un1versity Press, Oxford, 1954). 
v. LANGMUIR PROBE MEASUREMENTS IN THE MAGNETIC MIRROR MACHINE

K. A. Connor

The machine on which experiments are carried out is the same magnetic mirror device described in previous progrese reports except for the thyratron trigger circuitry. The agtable multivibrator has been replaced by the SCR clreuit shown.

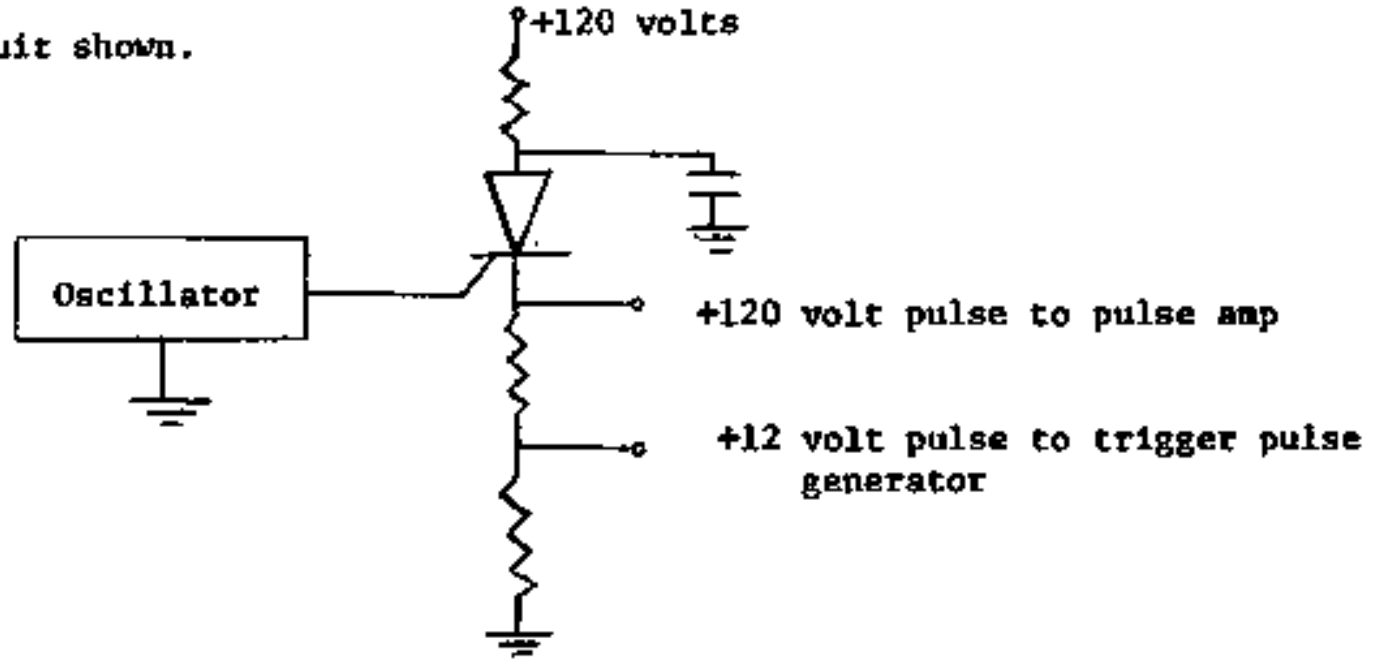

A modification of this efrcuit to include the functions of the delayed pulse generator and the pulse amplifiers is being constructed. The macbine may be operated in efther a single or double power pulse code. The experiments reported below were carrfed out with a $100 \mathrm{kH}$ single pover pulse 300 times per second.

Electron temperature, density, and floating potential were measured with Langmuit probes. The first question to be anawered when one wishes to nake such meagurements is how the probe affects the plasma to be measured. If the plasma is perturbed too much, the information from the probe is usezess, One should expect worthwhle results from tangoutr probes in our apparatus for the following reasons. First, there is no noticeable change in the visible light produced when the probe is in place for measurements. Second, the output of a shlelded dianagnet1c loop shows a change of less than $10 \mathrm{z}$ wen the axial and radial probes are extended fully into the rachine. Third, as is 
noted below, the radfal densfty profile is approxinately symetric while the probes are obviously asymetrically introduced into the plasma. Finally, for the probe to operate such that its data is redsonable, the anount of charge drawn from the plagma nust not be an appreciable percentage of the total charge. The total charge is given by

$$
\begin{aligned}
& Q=\text { neV }=8 \times 10^{-6} \text { coulombs. } \\
& V \text { - plasma volume. }
\end{aligned}
$$

The charge drawn out by the probe is given by

$$
\begin{aligned}
\Delta Q=\int_{0}^{t} p & I_{o f}(0) e^{-t / \tau} d t=6 \times 10^{-8} \text { coulombs } \\
T & =\text { decay constent } \\
t_{P} & =t \text { tome between power pulses. }
\end{aligned}
$$

Thus, the charge drop due to the presence of the probe 1 s less than 17 of the total.

The probes used consist of a $1 / 8$ inch diameter brass welding rod, approxinately a centimeter In length, soldered to the center conductor of an RG 58A/U cable. The cable te placed inside a section of $1 / 4$ inch glass tubing and epoxied at both ends of the glass for vacuum geal.

The circuit shown below was used for the measureants made. ' $\mathrm{L}$ was $10 \mathrm{k} \Omega$ for the density and cemperature measurements and $1 \mathrm{kn}$ for the flgating potential measurement. $C$ is due to the capac1tance of the cable and the input capacitance of the Tektrontx 1 A6 preanplifter, end is approximately equal to $300 \mathrm{pF}$.

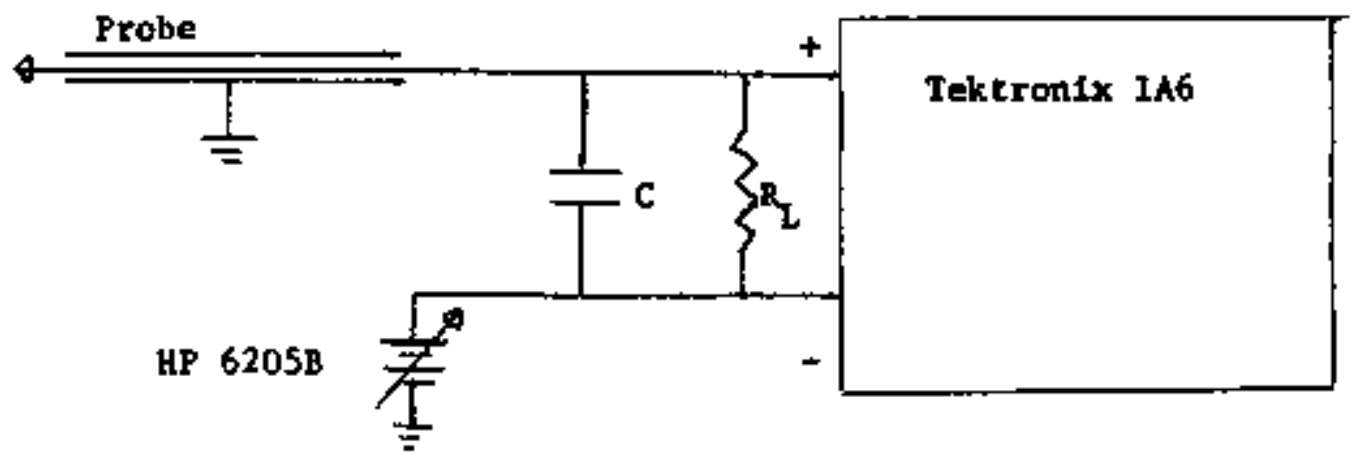


Figure 9 shows the theoretical aagaetsc field structure in which the measurements were made. The frequency of the mfcrowave power is $8.54 \mathrm{GHz}$ corresponding to cyclotion resonance at $\mathrm{B}-0.3050 \mathrm{w} / \mathrm{m}^{2}$. The figure shows where the resonance zones are for two different values of uagnet current. Except when Indicated, meagurements were made with $I_{\text {MAG }}-287$ axps.

F1gure 10 shows the V-I characteristic of the radial probe at $\mathrm{R}=3.5 \mathrm{~cm}$ 100 usec after the 2 usec power pulse. Notice that the high electron curtent region does not show saturation in the expected fanner. This, however, 1s a common effect in strong magnetic flelds. The probe draws nore electrons off a field line than are there so electrons have to diffuse across the field 11nes. The rate at which they diffuge linits the current drawn.

Figure 11 shows the V-I characteriatic of the axial probe at $R=0$, $2=\$ 5.1 \mathrm{~cm}, 50$ usec after the power pulse. ( $z$ is measured from the midplane.) The hot component of the electron temparature has been measured by other techniques--xrays, dlamggetic loop and $\overrightarrow{\mathrm{E}} \times \mathbf{B}$ analyzer. The electron temperature of the cold plasma component can be obtained fron the $V-1$ plots using the adrittance probe method. ${ }^{1}$ The method works as follows. $R_{\theta}$, the source resistance of the plasma, is the Inverse slope of the V-I characteristic at $V-V_{f}$, the floating potential. The Taylor expansion for $R_{s}$ givea the result that

$$
R_{s}=\frac{k T_{e}}{e} \frac{1}{I_{o I}}
$$

where: $I_{\text {of }}$ to the Ion staturation current $T_{e}$ is the electron temperature.

By measuring the slope at $\mathrm{V}=\mathrm{V}_{\mathrm{f}} \mathrm{kT}$, can be calculated. Figure 12 shows $\mathrm{kT}$ e $\mathrm{vs}$. time at $\mathrm{R}=3.5 \mathrm{~cm}, \mathrm{Z}=15.1 \mathrm{~cm}$. This method was ued because $1 \mathrm{t}$ avolds drawing large currents fron the plasma. 
PIGURE 9 CONTOURS OF CONSTANT MAGNETIC FIELD AMPLITUDE (R=1.021)
Location of resonance 200 es for $I_{\text {MAG }}=287$ amps and $I_{\text {MAG }}=289$ amps

$|\vec{B}|=\times I_{\text {MAG }}$ (anps) $\times 10.42 \mathrm{w} / \mathrm{m}^{2}$

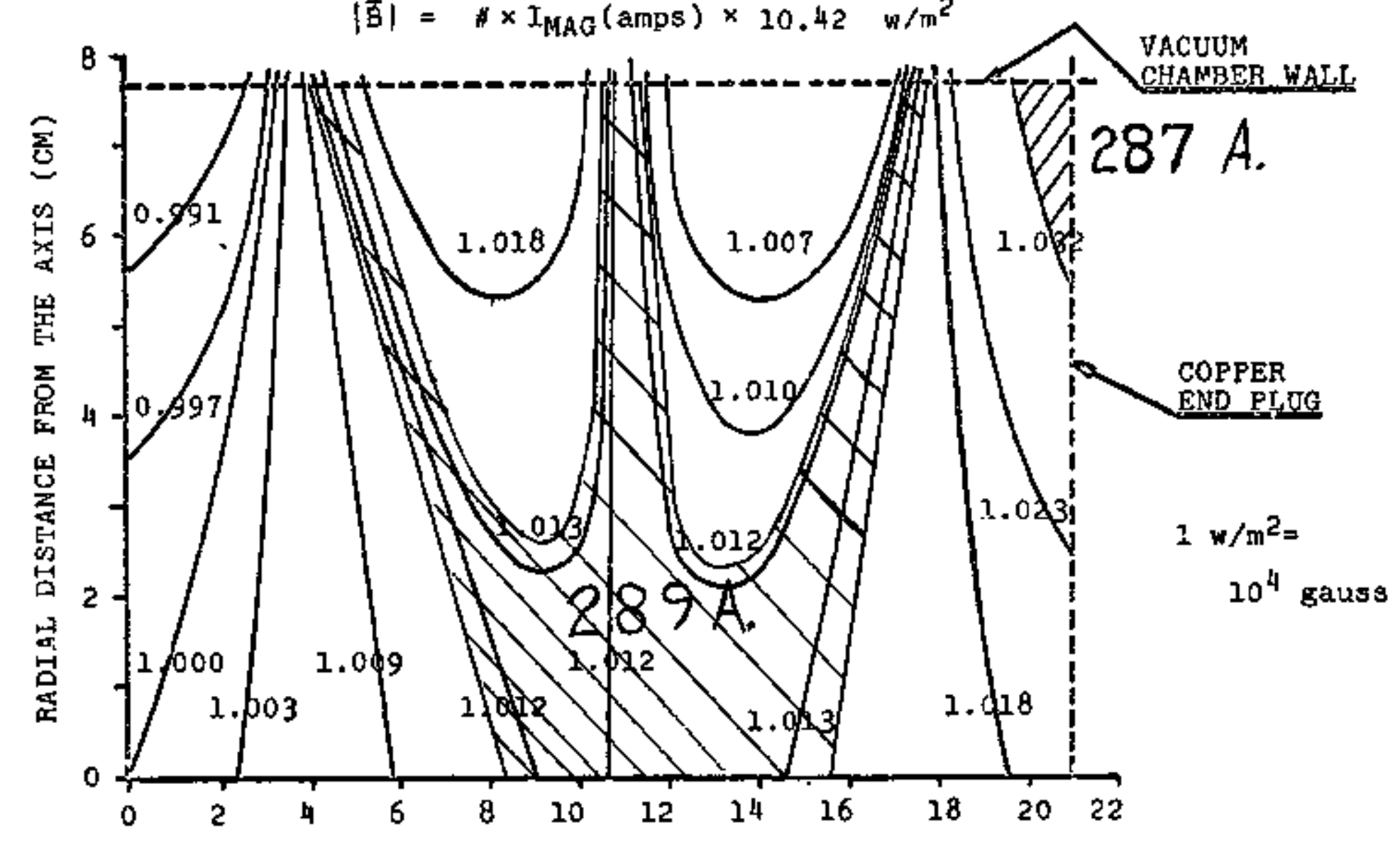

AXIAL DISTANCE FROM THE MIDPLANE (CM) 


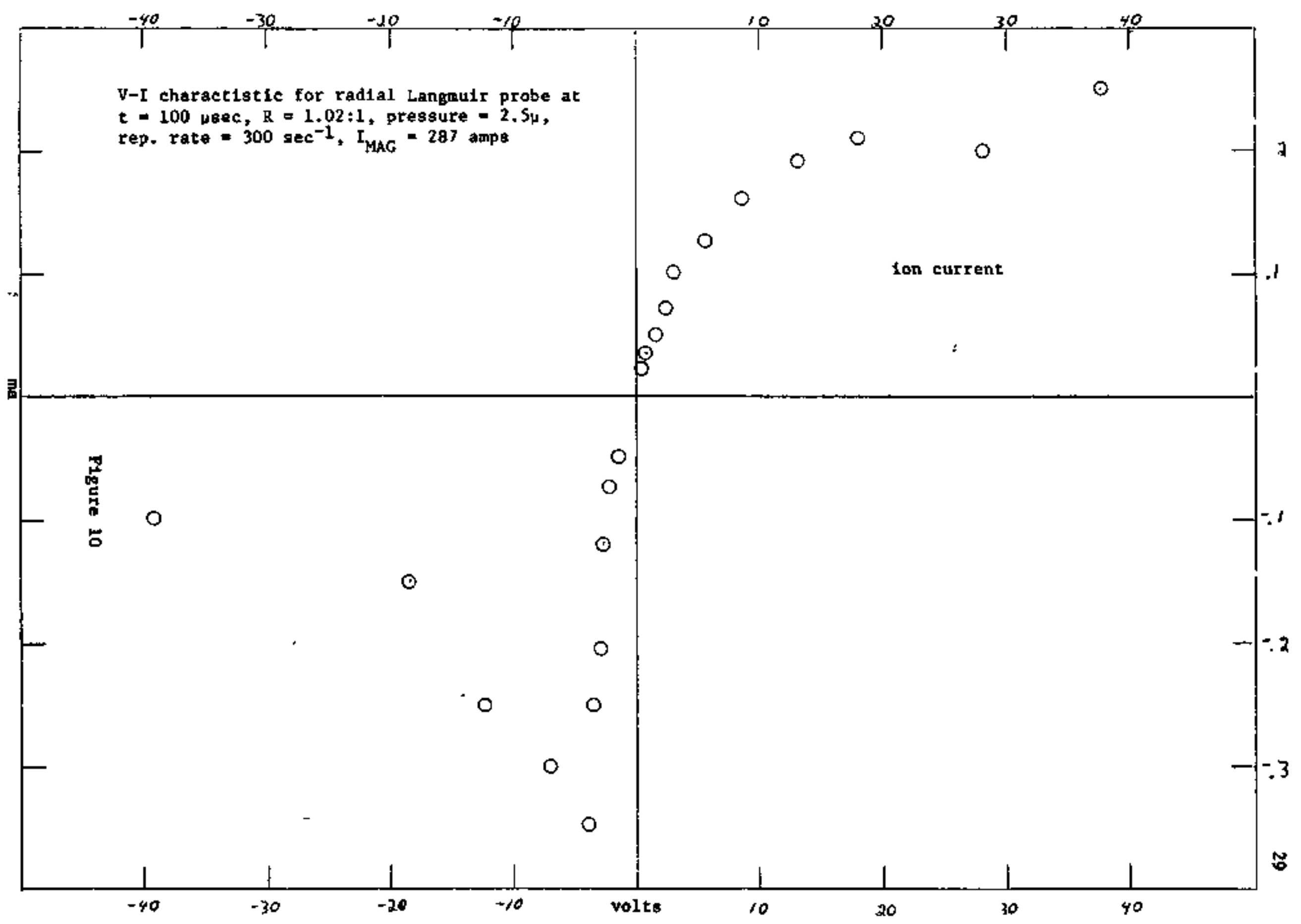




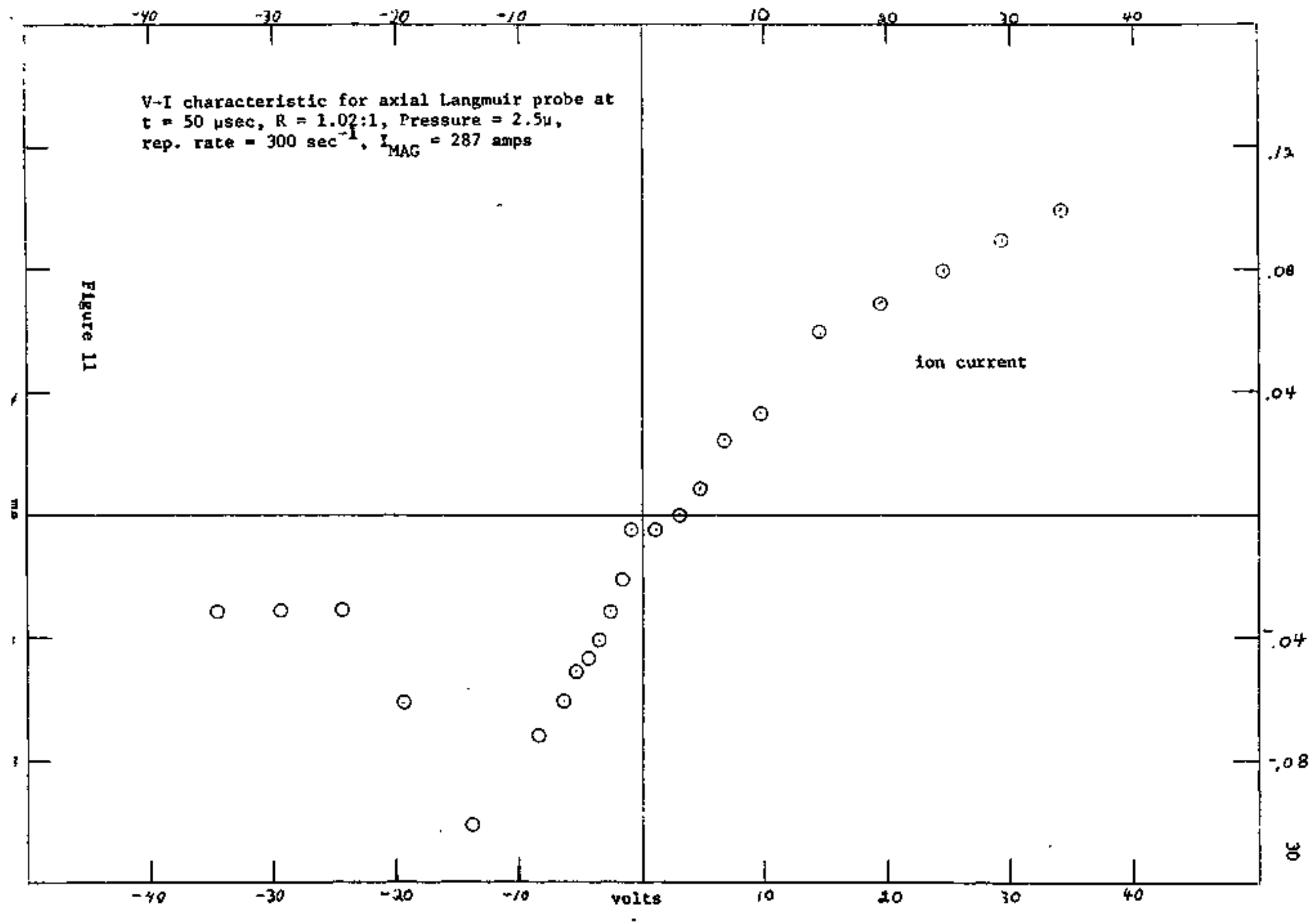


Electron temperature of cold component vs, time

$I_{\text {MAG }}=287$ amps

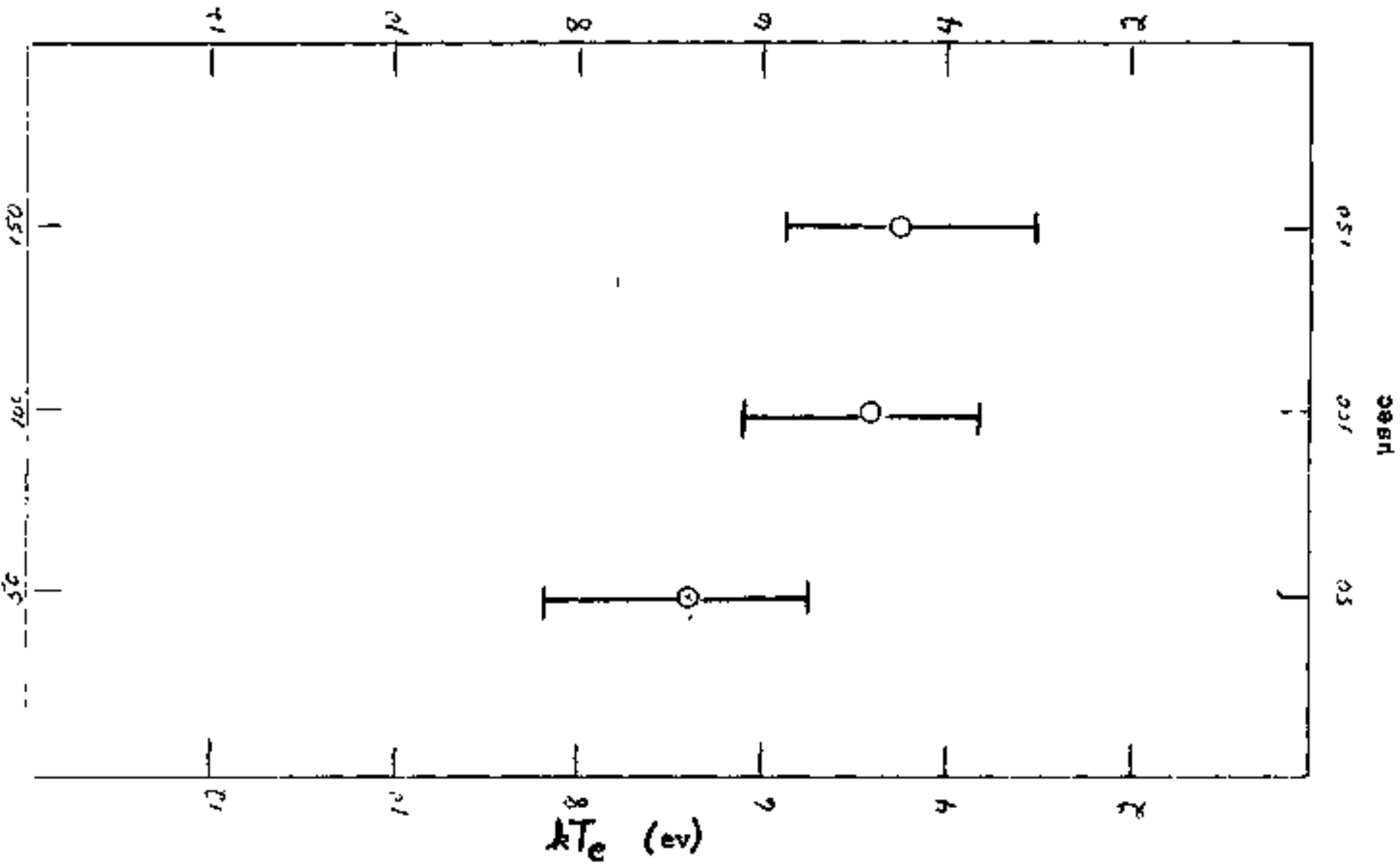

Figure 12 
The electron temperature can be calculated in another way. ${ }^{2}$ If therpal equilibrium is assumed, the current for $v_{P}>V>V_{f}$ is given by

$$
j(v)=\frac{I(v)}{A}=\frac{I\left(V_{p}\right)}{A} \exp \left[\frac{e\left(v-V_{p}\right)}{k T_{e}}\right] \text {. }
$$

When solved for the electron temperature we have

$$
T_{e}=\left[\frac{k}{e} \frac{d(\ln r(v))^{-1}}{d v}\right]^{-1}
$$

This method, being a bit more clunsy than the first, was used only as a check. For the case of $R=3.5 \mathrm{~cm}$ and $2-15.1 \mathrm{~cm}$ th gave 6.5 ev vg. $6.9 \mathrm{ev}$ for 50 ysec and 5.9 ev vs, 4.8 ev for 100 usec, showling reasonable agreerient.

(mce we know $\mathrm{kT}_{\mathrm{e}}$, the dens1ty may be derived. The lon saturation current may be expressed as follows

$$
I_{\text {o1 }}=\frac{1}{4} \text { neVkA } \quad\left(T_{i} \leq_{e}\right)
$$

where: $V^{*} \cdot\left[\frac{8 k T}{\pi m_{i}}\right]^{\frac{k}{x}}$ for a Maxwelliss

$\Lambda=$ effective probe area.

Figures 13 and 14 show $10 n$ saturation current as functions of $r, z$, and t. The corresponding densities range from $10^{9}$ to $10^{11} \mathrm{~cm}^{-3}$. Notlee the approximately syanetric forw of the radial profile. The minimun also occurred on the axid of the machine for the case where the resonance zone was deternined by $t_{M A G}=289$ (see Figure 9 ). The radial profile at different tines for this case fs shown in Figure 15. This indicates an annular structure to the plagma which has also shown up if the visible plasma ifght. Similar results have been obtained by Dandl, et al. ${ }^{3}$ The annular structure has shown up for heating zones both on and of the axis.

The floating potential can be measured directly making $\mathrm{R}_{\mathrm{L}}$ large, limited by the Input impedance of the Tektronix $1 \mathrm{Ag}$ plug-in unit, and $\mathrm{C}$ 


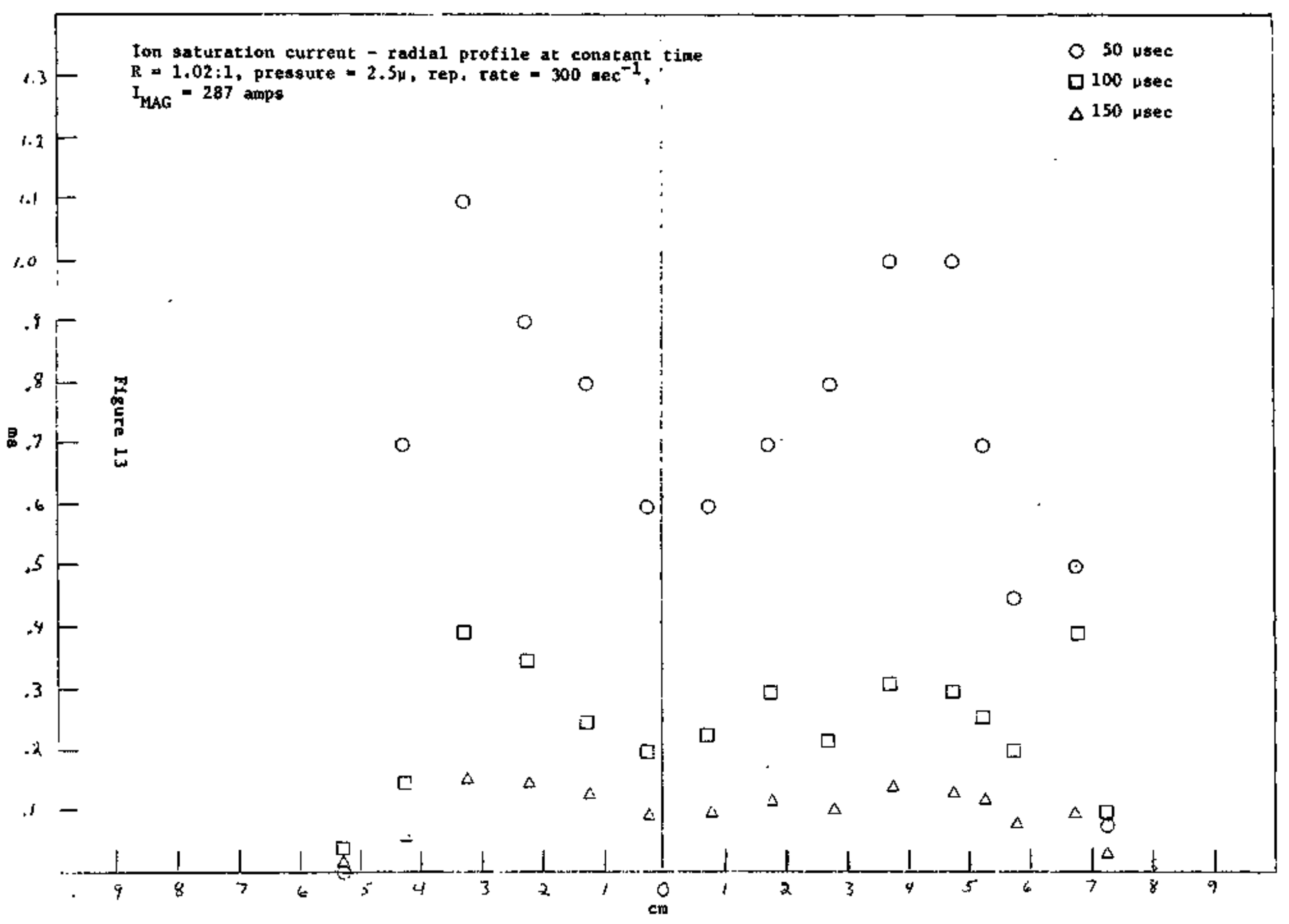




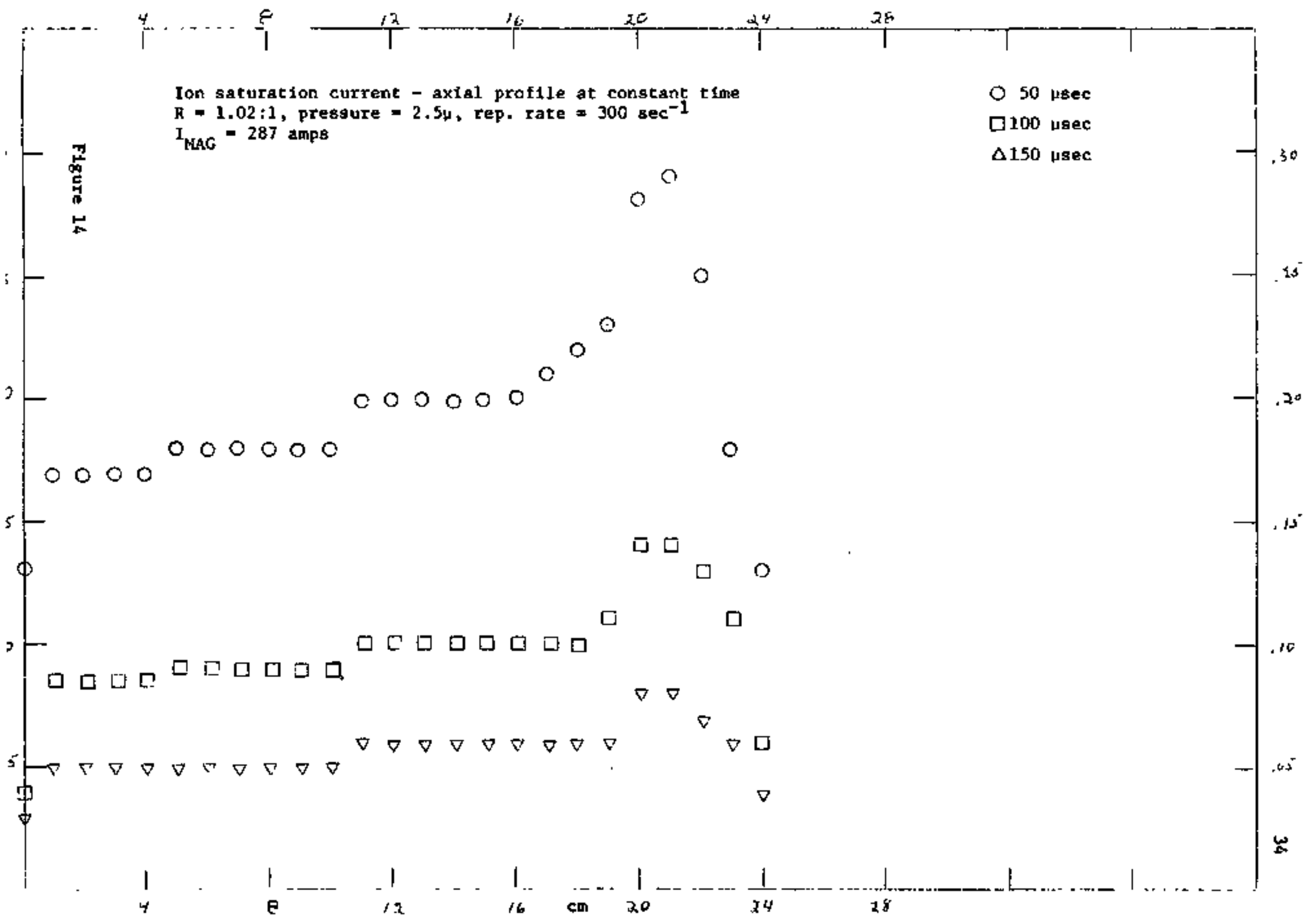




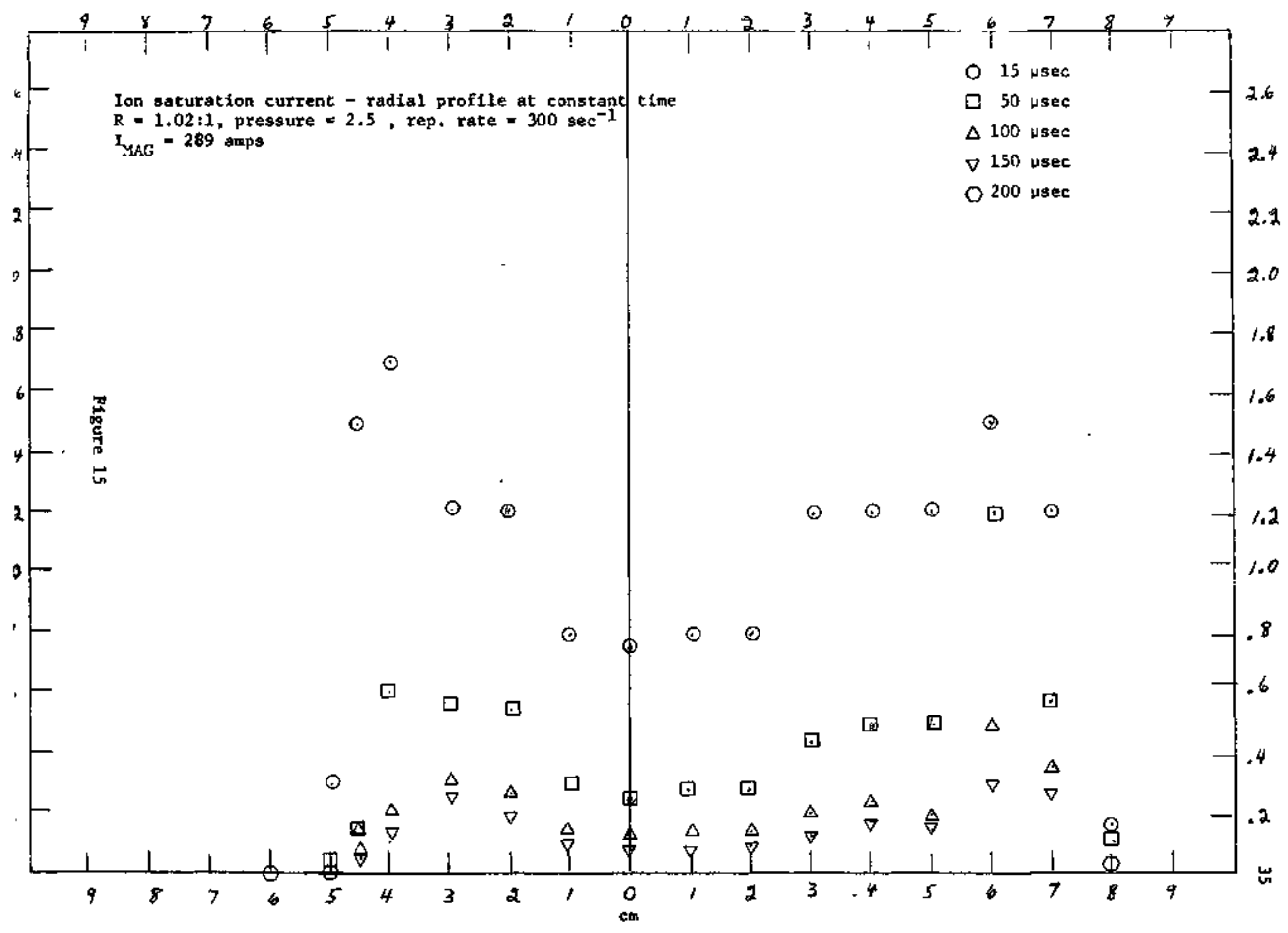


small, lianited by cable length and the Input capacitance tof the 1A6. A check was made to be sure that the decay of the floating potential was not due to the R-C time constant of the measurting circult. The circuit time constant was changed ustng both longer cables to increase $C$ and a $10: 1$ attenuator to Increase R. Both doubling the cable length and increasing the input impedance by 10 resulted in less than a $10 \%$ change in the value of the floating potential at all times. The result of the measurements fs show in Figure 16. For the worst case--occurring seldonly--the upper frequency 11m1t of the probe 18 given by

$$
\frac{1}{2 \pi \mathrm{fCR}}=2 \times 10^{3} \mathrm{~Hz}
$$

This is large enough to allow the measurements taken to be useful.

These meagurements have shown that it 18 possible to extend our measuring tools to include Langauir probes. This allowg us to chack the results obtalned agalnst previous measurements, make spatially localized measurements of plasma parameters, and extend our knowledge of the plasma parameters to longer times. The density measured wh probe techniques shows agreement to within an order of magnitude wth the fundamental mode ofcrowave cavity technique. The temperature is more difficult to compare since diamagnetic loop and $\vec{E} \times \vec{B}$ analyzer measurenents work for times to about 25 usec after the power pulse thile the probe data is for 50 psec after the power pulse and later. Figure 17 atows $\mathrm{kT}$ vs, time with an extension to short times for the same data contained In Figure 12, using data from a dianagnetlc loog and microwave densfty measurements under stmilar condtions. More measurements will be made to check the vartous techniques more thoroughly.

Fluctuations at $-40 \mathrm{kHz}$ in both ion saturation current and floating potential are observed near the edges of the plasma with resulting amplitude 
Floating potential - axial profile at constant tine

$\mathrm{k}=1.02: 1$, pressure $-2 . \mathrm{S}_{\mu}$, rep, rate $-300 \mathrm{sec}^{-1}$

$I_{M A G}=287$ \&mps

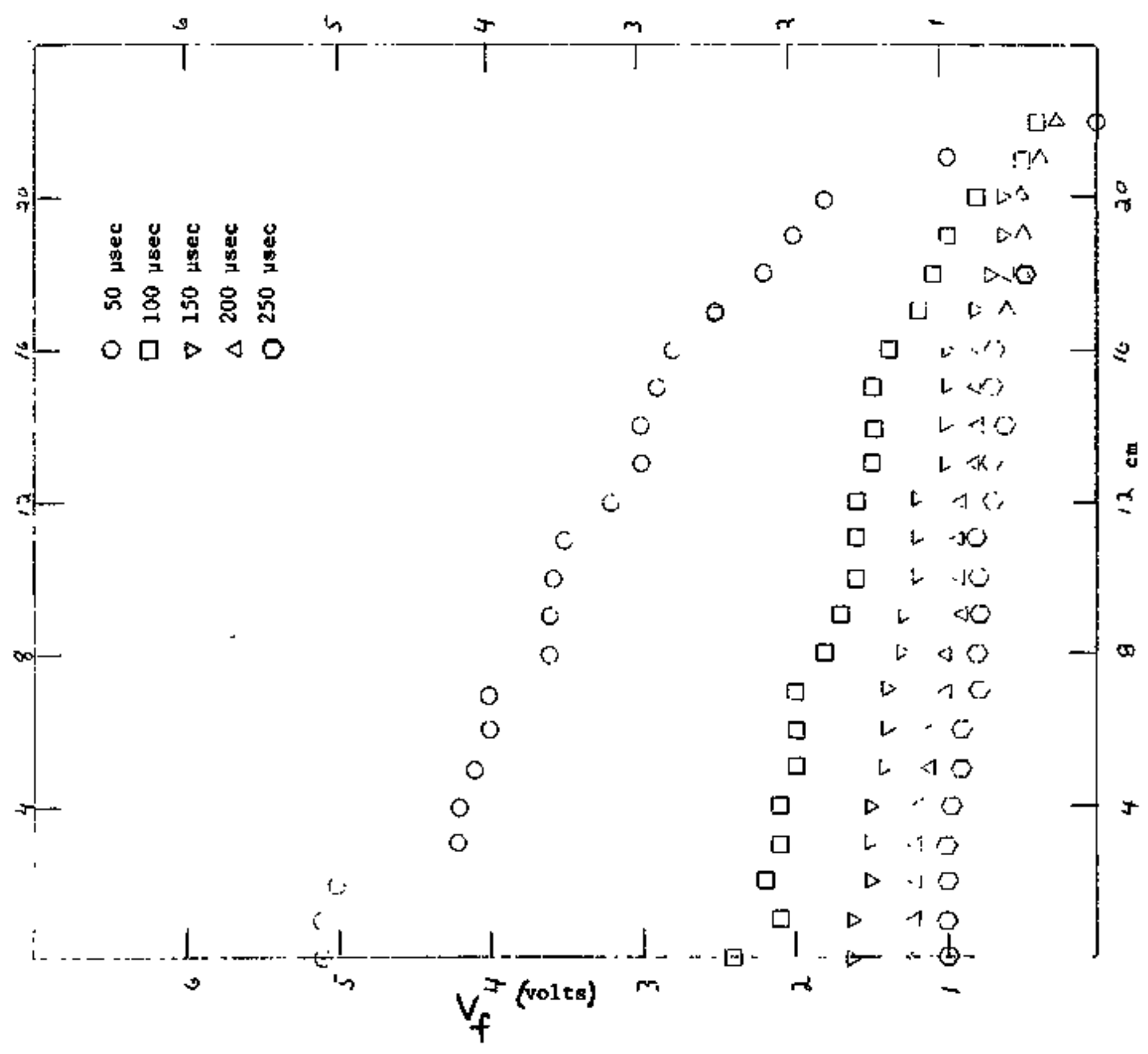




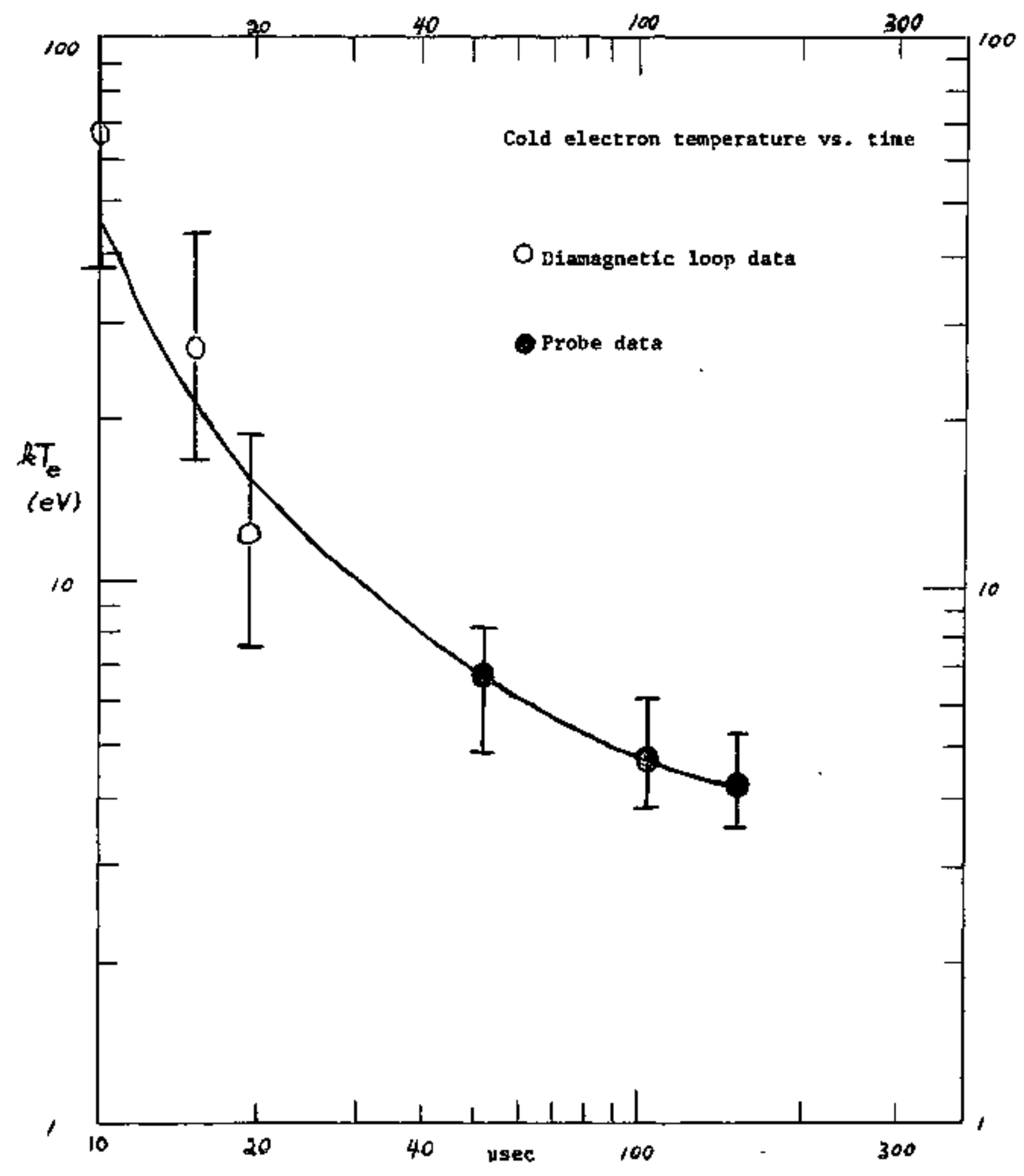

Figure 17 
vartations

$$
\left\langle\Delta n>/ n \simeq \frac{e^{<\Delta V_{f}}}{k T_{e}} \simeq 30-50 \% .\right.
$$

This effect will be studied when we take enough data to more completely parametertze the plasma produced in our machine.

\section{References}

1. J. C. Sprote, Rev, of Sct. Instr. 39, 1569 (1968).

2. F. F. Chen 1n Plasma Biagnostic Technlques, R. H. Huddlestone and S. L. Leonard, Eds. (Acadentc Press Inc., New York, 1965) Chap, 4.

3. Oak R1dge Natlonal Laboratory Thermonuclear Division Semiannual Progress Report for the period end1ng December $31,1968$. 